\title{
薄肉曲線ばりの板殼構造としての一解析法
}

\section{A METHOD FOR NUMERICAL ANALYSIS OF THIN-WALLED CURVED BEAMS CONSISTING OF PLATES AND SHELLS}

\author{
坂 井藤 一* - 中 村 秀 治** \\ By Fujikazu SAKAI and Hideharu NAKAMURA
}

\section{1.まえがき}

近年，構造解析技術の進歩に伴い，薄肉断面を有する 曲線ばりの解析もさかんに研究されるよらになった。薄 肉断面の場合と充実断面の場合とで, その力学的性状が 異なることは直線ばりにおいても認められている事実で あるが, 特に曲線ばりにおいては, ねじりの影響がより 厳しくなることからその相違は顕著となる。

薄肉曲線ばりの解析には, 通常, 断面形状の保持を前 提としてそりねじりの理論が適用されている。この最も 初期の取扱いは, 1932 年の Gottfeld による並列トラス 曲線ばりの研究1)であるといわれている。さらに,Uman$\mathrm{skij}^{2}$ により二軸対称 I 型ばりが取扱われ, Wansleben ${ }^{3)}$ によって曲線ばりのそりねじり理論がかなり進展した。 しかし, 彼の理論では相反作用則が充足されないといわ れている。Vlasov4) もまた有名な著書において理論を述 べている。最近では Dabrowski ${ }^{5}$ が精力的に研究を行 い, その成果を著書として公刊している。

一方, わが国においても, 1958 年の平井・倉西の研究6) 頃から曲線ばりのそりねじり理論が発展を見はじめ, 小 西・小松の基礎理論に関する研究 ${ }^{7}$, 小松らによる一連 の実用化研究 ${ }^{8)}$ (10), さらには, 倉西 ${ }^{11)}$, 島田 ${ }^{12)}$ そして深 沢 ${ }^{13), 14)}$ などにより基礎理論の詳細な展開と応用化がな された。他に, 幅員の広い場合を異方性扇形平板として取 扱う芳村の研究 ${ }^{15)}$, あるいは折線近似を行う多角形曲 線橋理論(遠藤) ${ }^{16}$ ) もある。このような基礎理論について の調査とともに, 複雑な曲線ばりの方程式を解いて設計 にとり入れるための手段もいろいろ考えられ, Becker ${ }^{17)}$ をはじめとする伝達マトリクス法や Fourier 級数解法 ${ }^{18)}$ がさかんに報告された。また, 最近では有限要素法（変 形法）がコンピューター解析に便利な点から適用される に至り, それとともに, 基礎理論の再検討も試みられて いる19)。

* 正会員 工博 川崎重工業鉄構事業部東京設計事務所

** 正会員 工修 電力中央研究所技術第二研究所
最近までの以上のような成果は, アメリカにおける研 究の現状とともに, ASCE の調查レポートにまとめられ ている ${ }^{20)}$ 。

断面形状の変化を考慮して曲線ばりを扱うことは，ご く最近に至り考えられるようになった。これは直線ばり の場合と同様に, 床版あるいはダイヤフラム, スチフナ 一などの補剛材と主構造たるはりの立体的関連挙動を解 明し, より合理的な設計法を追求しようとする立場に立 つものである。しかしながら，この解析はきわめて複雑 になるので, あまり研究報告はなされていない。従来の 研究は箱型はりに関するものである。Dabrowski ${ }^{5}$ ) は簡 便な取扱い法を示し，落合 ${ }^{21}$ は直線ばりに対する Vlasov 理論を応用している。能町・吉田 ${ }^{22}$ は曲線箱型はりを扇 形板と円筒殸の集合として, 変位一せん断方程式を用い て解析した。坂井も一般の曲線ばりを有限要素法 (帯板 法）の観点から解析し得ることを示し ${ }^{23)}$ ，また別に，板 款の基礎方程式と Vlasov の一般座標法を組合わせた曲 線箱型はりの解析法を示した ${ }^{24)}$ 。青野 ${ }^{25)}$ は Vlasov 法を より精密に適用し, 計算と実験の結果を対比している。 折板構造理論あるいは有限帯板法による曲線箱型はりの 解析は, Chu $ら^{26)}$, Scordelis $5^{27)}$, あるいは Buragohain $ら^{28)}$ によっても研究されている。

薄肉曲線ばりの立体挙動問題の一つは有効幅の問題で ある。これらについては, 小松ら ${ }^{29)}$, および薄木・菅 原 ${ }^{30}$ によって報告がなされており，芳村・韮沢 ${ }^{311}$ は Chu らの方法とほぼ同一な折板構造解析法の立場から検討を 加えている。

一方, アメリカでは Culver を中心とするグループ が, フランジおよびウェブの座屈安定問題やスチフナー 剛度の問題を論じてお放 ${ }^{32) ~ 34), ~ ま た, ~ A b d e l-S a y e d ~ の ~}$ 研究 ${ }^{35)}$ もる。この種の研究は米沢ら ${ }^{36}$ によっても報告 されている。

床板の問題は, 扇形平板の解析としてさかんに研究さ れている。Coull ら ${ }^{37}$ および Heins ら ${ }^{38}$ は解析法の検 討ならびに実験的確認を行い, Buragohain ${ }^{39)}$ は数值解 析の結果とそれらを対比している。また, Cheung(0) お 
よび大宮司ら ${ }^{41)}$ は有限帯板法の適用を行っている。

曲線ばりの振動問題はいろいろ研究されているが, 扇 形平板として取扱った米沢の研究 ${ }^{42)}$ や, Cheung の有限 帯板法による箱型はりの研究 ${ }^{43}$ などが本論の立場と特に 関連する。

本論文は, このような背景の下に薄肉曲線ばりの諸問 題を扱う一解析法を述べたものである。ここで述べる手 法は, 文献23)に基づくものであり, 直線構造において, 奥村・坂井が展開した手法 ${ }^{44)}$ を曲線構造に拡張したもの である。文献 44) は Cheung ${ }^{45)}$ あるいは Powell ら ${ }^{46)}$ の有限帯板法とほぼ同時期に独立に展開されたものであ るが, 次のような点で他と異なる特徴を見出すことがで きよう。

1）Kantrovich 法による有限要素法定式化。

2) weighted residuals method（重みつき残差法）の 有限要素法への適用。

3）有限帯板法の立体構造解析への適用。

4）解析解との重ね合わせ。

本論文の一つの意図はこれらの点にある。本解析法は Cheung $^{42)}$ あるいは Scordelis ${ }^{27)}$ が導いたものとほとんど 同一の内容を有するが, 重みつき残差法としての Galerkin 法を基礎として定式化している。その際, 重み関数 の選択によっては，相反作用則を充足しないことがある ことを指摘する。

本解析法はまた, 従来の曲線折板構造解析法に比べて 一般性がある。すなわち, 文献 22) あるいは 26) の方法 は, 限定された問題に対しては有効であろらが, 異方性 板フランジの場合や, 振動・座屈問題に対しては適用が 困難となろう。また, 一般に応力法は変位法に比べて数 值計算上，取扱いが面倒になると思われる。

本報告では, 二, 三の簡単な例題に対する計算および曲 線箱型はりの模型実験を行い, 本解析法が実用上十分 な結果を与えることを示す。紙面の都合からここでは 静的解析の展開にとどめてある。振動解析などのより複 雑な問題への応用については次の機会に譲るが, 薄肉曲 線ばりにおけるいろいろの問題, たとえば, 断面変形挙 動およびそれに関連したダイヤフラム, スチフナーの効 果算定, 床板の計算, あるいはフランジ, ウェブの座屈 安定などの問題が, 本解析法の応用により解析されるも のと思われる。

\section{2. 解析理論}

\section{(1) 概 要}

この理論は有限要素法の一つの考え方に基づいてお り, 参考文献 44) で薄肉直線ばりについて述べた手法を
薄肉曲線ばりに拡張したものである。

円弧曲線を描く薄肉曲線ばり（図一1）は，ほとんどが 扇形平板と円筒款から構成されているので, 曲線ばりを このような構成要素の集合体として解析する。そのため に各要素について, 変形は節線変位とある仮定された内 挿関数で表わされるものとし,変分原理を適用して,節線 外力と節線変位を結びつける要素の剛性マトリクスを誘 導する。その際, 扇形板要素については極座標で表示さ れた平衡方程式, 曲板要素については Donnell の理論式 を用いる。誘導の手順は直線ばりの場合と同様であるが， 扇形板要素の場合, 重みつき残差法としての Galerkin 法を用いる際, 若干の配慮が必要であり, また剛性マト リクスの成分を陽に求めるための積分が煩雑になるの で，数值積分を利用する。また扇形板要素では，扇形の 鉄筋コンクリート床版あるいは鋼床版などへの適用を想 定して，異方性を考慮している。

全部の要素についての剛性マトリクスを重ね合わせれ ば, はり全体の節線外力と節線変位の関係式が導かれ る。これは軸方向座標について 4 階の線型連立常微分方 程式の形を持ち, その解法は直線ばりの場合と同様であ る。本論文の数值計算例では, すべて Fourier 級数解 法を用いている。

\section{（2）扇形板要素の剛性マトリクスの誘導}

図一1に示すような扇形板および曲板要素からなる構 造系を考え, 点 $i, i^{\prime}, j, j^{\prime}$ で囲まれた要素を扇形板要素 $i j$ とよぶことにし，また $\widehat{i i^{\prime}}$ および $\widehat{j j^{\prime}}$ を節線 $i i^{\prime}$ およ び節線 $j j^{\prime}$ とよぶことにする。

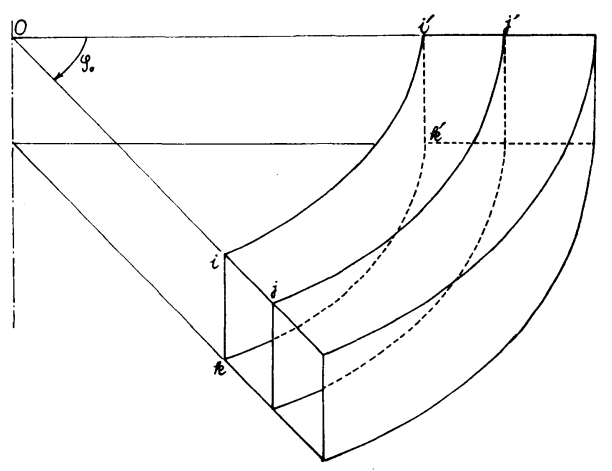

図一1 薄肉曲線ばり

図一2 に示すように, 基準座標系を $O-r-y-\varphi$ 亡し, 要 素の局所座標系を $O^{\prime}-s$ とする。基準座標軸方向の変位 をそれぞれ $u, v, w$ とし, $\varphi$ 軸まわりの回転を $\theta$ とす る。節線 $i i^{\prime}$ における曲率半径を $R_{i}$, また各座標軸方 向の変位, 回転をそれぞれ $u_{i}, v_{i}, w_{i}, \theta_{i}$ とし, 同様に 節線 $j j^{\prime}$ における曲率半径, 変位, 回転をそれぞれ $R_{j}$, $u_{j}, v_{j}, w_{j}, \theta_{j}$ と表わす。また, 要素の板幅を $b$ とす 


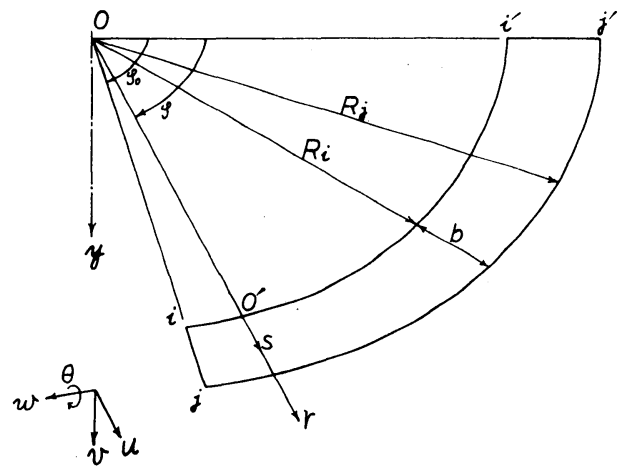

図一2 扇形板 要 索

る。

扇形板が半径方向とはり軸方向に直交異方性を有する ものとし, 面内変形と面外変形の間に相互の連成がない ものと仮定すれば, 次に述べる手順で扇形板要素の剛性 マトリクスを導くことができる。等方性を有する場合は この特殊な場合と考えればよい。

極座標表示された平板の平衡方程式は次の 3 式であ る。

$$
\begin{aligned}
& \frac{1}{r} N_{\varphi}^{\prime}+N^{\cdot}{ }_{\varphi r}+\frac{2}{r} N_{\varphi r}+p_{\varphi}=0 \cdots \cdots \cdots \cdots(1 \cdot \mathrm{a}) \\
& \frac{1}{r} N^{\prime}{ }_{\varphi r}+N_{r} \cdot+\frac{1}{r}\left(N_{r}-N_{\varphi}\right)+p_{r}=0 \cdots \cdots(1 \cdot \mathrm{b}) \\
& \frac{1}{r^{2}} M_{\varphi}^{\prime \prime}+\frac{2}{r} M^{\prime}{ }_{\varphi r}+M_{r} \cdot \cdot \\
& \quad+\frac{1}{r}\left(\frac{2}{r} M^{\prime}{ }_{\varphi r}+2 M_{r} \cdot-M_{\varphi} \cdot\right)+p_{y}=0 \cdots(1 \cdot \mathrm{c})
\end{aligned}
$$

ここで, ( ) $)^{\prime}=\partial() / \partial \varphi,(\quad)=\partial(\quad) / \partial r$ とし, $\mathrm{N}_{\varphi}, N_{r}, N_{\varphi r}$ は応力, $M_{\varphi}, M_{r}, M_{\varphi r}$ は曲げおよびね じりモーメントであり， $p_{\varphi}, p_{r}, p_{y}$ はそれぞれ $\varphi, r, y$ 軸方向の単位面積当たり分布荷重である。

面内ひずみを $\varepsilon_{\varphi}, \varepsilon_{r}, r_{\varphi r}$, 面外ひずみを $\chi_{\varphi}, \chi_{r}, \chi_{\varphi r}$ とすれば, 応力とひずみの関係は次式で表わされる。

$$
\begin{aligned}
& \left\{\begin{array}{l}
N_{\varphi} \\
N_{r} \\
N_{\varphi r}
\end{array}\right\}=\left[\begin{array}{ccc}
F_{\varphi} & \nu_{r} F_{\varphi} & 0 \\
\nu_{\varphi} F_{r} & F_{r} & 0 \\
0 & 0 & F_{k}
\end{array}\right]\left\{\begin{array}{l}
\varepsilon_{\varphi} \\
\varepsilon_{r} \\
\gamma_{\varphi r}
\end{array}\right\} \\
& \left\{\begin{array}{l}
M_{\varphi} \\
M_{r} \\
M_{\varphi r}
\end{array}\right\}=\left[\begin{array}{ccc}
D_{\varphi} & \nu_{r} D_{\varphi} & 0 \\
\nu_{\varphi} D_{r} & D_{r} & 0 \\
0 & 0 & D_{k}
\end{array}\right\}\left\{\begin{array}{c}
\chi_{\varphi} \\
\chi_{r} \\
2 \chi_{\varphi r}
\end{array}\right\}
\end{aligned}
$$

ひずみと変位の関係は次式で表示される。

$$
\begin{aligned}
& \varepsilon_{\varphi}=\frac{u}{r}+\frac{1}{r} w^{\prime} \ldots \ldots \\
& \varepsilon_{r}=u \cdot \ldots \ldots \ldots \ldots \ldots \ldots \ldots \ldots \ldots \\
& r_{\varphi r}=\frac{1}{r} u^{\prime}+w^{\cdot}-\frac{w}{r} \\
& \chi_{\varphi}=-\frac{1}{r} v^{\cdot}-\frac{1}{r^{2}} v^{\prime \prime}
\end{aligned}
$$

$\chi_{r}=-v^{*}$

$$
\chi_{\varphi r}=-\frac{1}{r} v^{\prime}+\frac{1}{r^{2}} v^{\prime}
$$

要素 ijについて変位関数を次のように仮定する。

$$
w(\varphi, s)=w^{(i)}(s) w_{i}(\varphi)
$$$$
+w^{(j)}(s) w_{j}(\varphi)
$$

$u(\varphi, s)=u^{(i)}(s) u_{i}(\varphi)+u^{(j)}(s) u_{j}(\varphi)$

$v(\varphi, s)=v^{(i)}(s) v_{i}(\varphi)+\theta^{(i)}(s) \theta_{i}(\varphi)$

$+v^{(j)}(s) v_{j}(\varphi)+\theta^{(j)}(s) \theta_{j}(\varphi)$

ただし，

$$
\begin{aligned}
& w^{(i)}(s)=u^{(i)}(s)=1-\frac{s}{b} \\
& w^{(j)}(s)=u^{(j)}(s)=\frac{s}{b} \quad \cdots . \\
& v^{(i)}(s)=1-\frac{3}{b^{2}} s^{2}+\frac{2}{b^{3}} s^{3} \\
& \theta^{(i)}(s)=s-\frac{2}{b} s^{2}+\frac{1}{b^{2}} s^{3} \\
& v^{(j)}(s)=\frac{3}{b^{2}} s^{2}-\frac{2}{b^{3}} s^{3} \cdots \\
& \theta^{(j)}(s)=-\frac{1}{b} s^{2}+\frac{1}{b^{2}} s^{3} \cdots
\end{aligned}
$$

式 (1) の平衡方程式に対して,式(4)のように仮定され た変位関数を用いて, 重みつき残差法としての Galerkin 法を適用寸れば，次の 8 式を導くことができる。

$$
\begin{aligned}
& \int_{0}^{b}\left(\frac{1}{R_{i}+s} N_{\varphi}^{\prime}+N_{\varphi r}+\frac{2}{R_{i}+s} N_{\varphi r}+p_{\varphi}\right)\left(R_{i}\right. \\
& +s) w^{(i)} d s=0 \\
& \int_{0}^{b}\left(\frac{1}{R_{i}+s} N_{\varphi}{ }^{\prime}+N_{\varphi r}+\frac{2}{R_{i}+s} N_{\varphi r}+p_{\varphi}\right)\left(R_{i}\right. \\
& +s) w^{(j)} d s=0 \\
& \int_{0}^{b}\left\{\frac{1}{R_{i}+s}-N_{\varphi r^{\prime}}+N_{r}+\frac{1}{R_{i}+s}\left(N_{r}-N_{\varphi}\right)\right. \\
& \left.+p_{r}\right\}\left(R_{i}+s\right) u^{(i)} d s=0 \\
& \int_{0}^{b}\left\{\frac{1}{R_{i}+s} N_{\varphi r^{\prime}}+N_{r} \cdot \frac{1}{R_{i}+s}\left(N_{r}-N_{\varphi}\right)\right. \\
& +\operatorname{pr}\}\left(R_{i}+s\right) u^{(j)} d s=0 \text {. } \\
& \int_{0}^{b}\left\{\frac{1}{\left(R_{i}+s\right)^{2}} M_{\varphi}^{\prime \prime}+\frac{2}{R_{i}+s} M_{\varphi r}{ }^{\prime}+M_{r} \cdot \cdot\right. \\
& +\frac{1}{R_{i}+s}\left(\frac{2}{R_{i}+s} M_{\varphi r}{ }^{\prime}+2 M_{r} \cdot-M_{\varphi} \cdot\right) \\
& \left.+p_{y}\right\}\left(R_{i}+s\right) v^{(i)} d s=0 \\
& \int_{0}^{b}\left\{\frac{1}{\left(R_{i}+s\right)^{2}} M_{\varphi}^{\prime \prime}+\frac{2}{R_{i}+s} M_{\varphi r} \cdot+M_{r} \cdot \cdot\right. \\
& +\frac{1}{R_{i}+s}\left(\frac{2}{R_{i}+s} M_{\varphi r}{ }^{\prime}+2 M_{r} \cdot-M_{\varphi} \cdot\right) \\
& \left.+p_{y}\right\}\left(R_{i}+s\right) v^{(j)} d s=0 \\
& \int_{0}^{b}\left\{\frac{1}{\left(R_{i}+s\right)^{2}} M_{\varphi}^{\prime \prime}+\frac{2}{R_{i}+s} M_{\varphi r}{ }^{\prime}+M_{r} \cdot \cdot\right.
\end{aligned}
$$




$$
\begin{aligned}
& +\frac{1}{R_{i}+s}\left(\frac{2}{R_{i}+s} M_{\varphi r^{\prime}}+2 M_{r} \cdot-M_{\varphi} \cdot\right) \\
& \left.+p_{y}\right\}\left(R_{i}+s\right) \theta^{(i)} d s=0 \\
& \int_{0}^{b}\left\{\frac{1}{\left(R_{i}+s\right)^{2}} M_{\varphi}^{\prime \prime}+\frac{2}{R_{i}+s} M_{\varphi r}{ }^{\prime}+M_{r} \cdot \cdot\right. \\
& +\frac{1}{R_{i}+s}\left(\frac{2}{R_{i}+s} M_{\varphi r^{\prime}}+2 M_{r} \cdot-M_{\varphi} \cdot\right) \\
& \left.+p_{y}\right\}\left(R_{i}+s\right) \theta^{(j)} d s=0 \text {. }
\end{aligned}
$$

ここで, 残差に対する重みとして内挿関数 $u^{(i)}, u^{(j)}$, ……を $\left(R_{i}+s\right)$ 倍したものを用いていることに注目する 必要がある (この点に関しては脚注参照)。

式(6)の $\partial^{2} / \partial s^{2}$ 項および $\partial / \partial s$ 項を部分積分すれば, $w^{(i)}, w^{(j)}, u^{(i)}, u^{(j)}, v^{(i)}, v^{(j)}, \theta^{(i)}, \theta^{(j)}$ の定義によ って次式が導かれる*。

$$
\begin{aligned}
& N_{\varphi r}{ }^{(i)}(\varphi)=-\frac{1}{R_{i}} \int_{0}^{b}\left\{\left(N_{\varphi}{ }^{\prime}+N_{\varphi r}\right) w^{(i)}\right. \\
& -N_{\varphi r}\left(R_{i}+s\right) \dot{w}^{(i)}+p_{\varphi}\left(R_{i}\right. \\
& \left.+s) w^{(i)}\right\} d s \\
& N_{\varphi \gamma}{ }^{(j)}(\varphi)=-\frac{1}{R_{j}} \int_{0}^{b}\left\{\left(N_{\varphi}{ }^{\prime}+N_{\varphi r}\right) w^{(j)}\right. \\
& -N_{\varphi r}\left(R_{i}+s\right) \dot{w}^{(j)}+p_{\varphi} \\
& \left.+\left(R_{i}+s\right) w^{(j)}\right\} d s \\
& N_{r}^{(i)}(\varphi)=-\frac{1}{R_{i}} \int_{0}^{b}\left\{\left(N_{\varphi r^{\prime}}-N_{\varphi}\right) u^{(i)}\right. \\
& -N_{r}\left(R_{i}+s\right) \dot{u}^{(i)}+p_{r}\left(R_{i}\right. \\
& \left.+s) u^{(i)}\right\} d s \\
& N_{r}{ }^{(j)}(\varphi)=-\frac{1}{R_{j}} \int_{0}^{b}\left\{\left(N_{\varphi r^{\prime}}-N_{\varphi}\right) u^{(j)}\right. \\
& -N_{r}\left(R_{i}+s\right) \dot{u}^{(j)}+p_{r}\left(R_{i}\right. \\
& \left.+s) u^{(j)}\right\} d s \text {. } \\
& Q_{r}^{(i)}(\varphi)=-\frac{1}{R_{i}} \int_{0}^{b}\left\{\frac{1}{R_{i}+s}\left(M_{\varphi}^{\prime \prime}+2 M_{\varphi r^{\prime}}\right) v^{(i)}\right.
\end{aligned}
$$

（脚注）重みつき残差法としての Galerkin 法あるいは仮想仕 事の原理は最小ポテンシャルエネルギー原理と比べて, 自己 随伴型のみならず非自己随伴型の微分方程式に対しても適用 可能であることが利点である。しかしながら，その場合変位 関数に課せられる条件は変分学上許容でありさえすればよ く，その結果として剛性マトリックスの対称性などが必ずし も保証されないことは注意すべきである。

現在扱っている微小変位弾性学の問題においては, 方程式 は自己随伴型であり，したがって Maxwell-Betti の相反作 用則が成立つことがわかっている。最小ポテンシャルエネル ギー原理から出発する時には, 必然的にこの法則は充足され るけれども, Galerkin 法を基礎にする時には, 重み関数の選 択に注意を払わないとこの法則と矛盾する結果を得ることが ある。本論では前述のような重み関数を選ぶことによって, マトリックスの対称性, ひいては相反作用則の成立を確保し ている。この結果は最小ポテンシャルエネルギー原理に基づ く Ritz 法の場合とほとえど同じことになる。曲線構造の場 合には仮想仕事の原理を適用するに際してもこの点は同様で あることを指摘しておく。

この誘導過程の詳細は文献 44）を参照されたい。

$$
\begin{aligned}
& -\left(2 M_{\varphi r^{\prime}}-M_{\varphi}\right) \dot{v}^{(i)} \\
& +M_{r}\left(R_{i}+s\right) \ddot{v}^{(i)} \\
& \left.+p_{y}\left(R_{i}+s\right) v^{(i)}\right\} d s \cdots \cdots \cdots \cdots(7 \cdot \mathrm{e}) \\
Q_{r}^{(j)}(\varphi)= & -\frac{1}{R_{j}} \int_{0}^{b}\left\{\frac{1}{R_{i}+s}\left(M_{\varphi}^{\prime \prime}+2 M_{\varphi r^{\prime}}\right) v^{(j)}\right. \\
& -\left(2 M_{\varphi r^{\prime}}-M_{\varphi}\right) \dot{v}^{(j)} \\
& +M_{r}\left(R_{i}+s\right) \ddot{v}^{(j)} \\
& \left.+p_{y}\left(R_{i}+s\right) v^{(j)}\right\} d s \cdots \cdots \cdots \cdots(7 \cdot \mathrm{f}) \\
M_{r}^{(i)}(\varphi)= & -\frac{1}{R_{i}} \int_{0}^{b}\left\{\frac{1}{R_{i}+s}\left(M_{\varphi}^{\prime \prime}+2 M_{\varphi r^{\prime}}\right) \theta^{(i)}\right. \\
& -\left(2 M_{\varphi r^{\prime}}-M_{\varphi}\right) \dot{\theta}(i) \\
& +M_{r}\left(R_{i}+s\right) \ddot{\theta}^{(i)} \\
& \left.+p_{y}\left(R_{i}+s\right) \theta^{(i)}\right\} d s \cdots \cdots \cdots \cdots \cdots(7 \cdot \mathrm{g}) \\
& \left.+p_{y}\left(R_{i}+s\right) \theta^{(j)}\right\} d s \cdots \cdots \cdots \cdots(7 \cdot \mathrm{h}) \\
M_{r}^{(j)}(\varphi)= & \frac{1}{R_{j}} \int_{0}^{b}\left\{\frac { 1 } { R _ { i } + s } \left(M_{\varphi}^{\prime \prime}+2 M_{\left.\varphi r^{\prime}\right) \theta^{(i)}}\right.\right. \\
& -\left(2 M_{\varphi r^{\prime}}-M_{\varphi}\right) \dot{\theta}(j) \\
& +M_{r}\left(R_{i}+s\right) \ddot{\theta}^{(j)} \\
&
\end{aligned}
$$

ここで, $N_{\varphi r^{(i)}}, N_{\varphi r}{ }^{(j)}, N_{r}^{(i)}, N_{r}^{(j)}, Q_{r}^{(i)}, Q_{r}^{(j)}$, $M_{r}{ }^{(i)}, M_{r}{ }^{(j)}$ はそれぞれ，節線 $i i^{\prime}, j j^{\prime}$ に作用する $\varphi, r$, $y$ 軸方向外力荷重および $\varphi$ 軸まわり外力モーメントで ある。ただし， $Q_{r}{ }^{(i)}, Q_{r}{ }^{(j)}$ は次式で表わされる等価せ ん断力を考えている。

$$
\begin{aligned}
Q_{r}^{(i)}= & -\left[M_{r} \cdot \frac{2}{R_{i}+s} M_{\varphi}^{\prime} r\right. \\
& \left.+\frac{1}{R_{i}+s}\left(M_{r}-M_{\varphi}\right)\right]_{s=0} \\
Q_{r}{ }^{(j)}= & {\left[M_{r} \cdot+\frac{2}{R_{i}+s} M_{\varphi r}{ }^{\prime}\right.} \\
& \left.+\frac{1}{R_{i}+s}\left(M_{r}-M_{\varphi}\right)\right]_{s=b}
\end{aligned}
$$

式 (7) から式 (2)，(3)，(4)，(5) を利用して変形すれ ば，次のマトリクス表示式が導かれる**。

$$
\begin{aligned}
\{\boldsymbol{P}\}= & {\left[\left[\boldsymbol{K}_{1}{ }^{p l}\right]\left(\frac{d}{d \varphi}\right)^{4}+\left[\boldsymbol{K}_{2}{ }^{p l}\right]\left(\frac{d}{d \varphi}\right)^{2}\right.} \\
& \left.+\left[\boldsymbol{K}_{3}{ }^{p l}\right]\left(\frac{d}{d \varphi}\right)+\left[\boldsymbol{K}_{4}^{p l}\right]\right]\{\boldsymbol{\delta}\} \cdots \cdots
\end{aligned}
$$

ここで, $\{\boldsymbol{P}\}$ および $\{\boldsymbol{d}\}$ は節線外力および節線変位 のベクトルであり，次に示すものである。

$$
\left.\{\boldsymbol{P}\}=\left\{\begin{array}{ll}
N_{\varphi r^{(i)}}(\varphi) \\
N_{r}{ }^{(i)} & (\varphi) \\
Q_{r}{ }^{(i)} & (\varphi) \\
M_{r}{ }^{(i)} & (\varphi) \\
N_{\varphi r}{ }^{(j)} & (\varphi)
\end{array}\right\},\{\boldsymbol{\delta}\}=\begin{array}{l}
w_{i}(\varphi) \\
u_{i}(\varphi) \\
v_{i}(\varphi) \\
\theta_{i}(\varphi) \\
w_{j}(\varphi)
\end{array}\right\}
$$

** このように本論では変分原理を利用して偏微分方程式を常 微分方程式に変換する Kantrovich 法を基に有限帯板法 を定式化している。 


$$
\left.\mid \begin{array}{ll}
N_{r}{ }^{(j)} & (\varphi) \\
Q_{r}{ }^{(j)} & (\varphi) \\
M_{r}{ }^{(j)} & (\varphi)
\end{array}\right) \quad\left|\begin{array}{l}
u_{j}(\varphi) \\
v_{j}(\varphi) \\
\theta_{j}(\varphi)
\end{array}\right|
$$

$\left[\boldsymbol{K}_{1}^{p l}\right],\left[\boldsymbol{K}_{2}{ }^{p l}\right],\left[\boldsymbol{K}_{3}^{p l}\right]$ および $\left[\boldsymbol{K}_{4}^{p l}\right]$ は剛性マト リクスで次に示すものである。

a) $\left[\boldsymbol{K}_{1}^{p l}\right]$ マトリクス

$(i, j)=0$ (次に示す以外のマトリクス成分)

$$
\begin{aligned}
& (3,3)=\frac{D_{\varphi}}{R_{i}} \int_{0}^{b} \frac{v^{(i)} v^{(i)}}{\left(R_{i}+s\right)^{3}} d s \\
& (3,4)=\frac{D_{\varphi}}{R_{i}} \int_{0}^{b} \frac{\theta^{(i)} v^{(i)}}{\left(R_{i}+s\right)^{3}} d s \\
& (3,7)=\frac{D_{\varphi}}{R_{i}} \int_{0}^{b} \frac{v^{(j)} v^{(i)}}{\left(R_{i}+s\right)^{3}} d s \\
& (3,8)=\frac{D_{\varphi}}{R_{i}} \int_{0}^{b} \frac{\theta^{(j)} v^{(i)}}{\left(R_{i}+s\right)^{3}} d s \\
& (4,3)=\frac{D_{\varphi}}{R_{i}} \int_{0}^{b} \frac{v^{(i)} \theta^{(i)}}{\left(R_{i}+s\right)^{3}} d s \\
& (4,4)=\frac{D_{\varphi}}{R_{i}} \int_{0}^{b} \frac{\theta^{(i)} \theta^{(i)}}{\left(R_{i}+s\right)^{3}} d s \\
& (4,7)=\frac{D_{\varphi}}{R_{i}} \int_{0}^{b} \frac{v^{(j)} \theta^{(i)}}{\left(R_{i}+s\right)^{3}} d s \\
& (4,8)=\frac{D_{\varphi}}{R_{i}} \int_{0}^{b} \frac{\theta^{(j)\left(\theta^{i}\right)}}{\left(R_{i}+s\right)^{3}} d s \\
& (7,3)=\frac{D_{\varphi}}{R_{j}} \int_{0}^{b} \frac{v^{(i)} v^{(j)}}{\left(R_{i}+s\right)^{3}} d s \\
& (7,4)=\frac{D_{\varphi}}{R_{j}} \int_{0}^{b} \frac{\theta^{(i)} v^{(j)}}{\left(R_{i}+s\right)^{3}} d s \\
& (7,7)=\frac{D_{\varphi}}{R_{j}} \int_{0}^{b} \frac{v^{(j)} v^{(j)}}{\left(R_{i}+s\right)^{3}} d s \\
& (7,8)=\frac{D_{\varphi}}{R_{j}} \int_{0}^{b} \frac{\theta^{(j)} v^{(j)}}{\left(R_{i}+s\right)^{3}} d s \\
& (8,3)=\frac{D_{\varphi}}{R_{j}} \int_{0}^{b} \frac{v^{(i)} \theta^{(j)}}{\left(R_{i}+s\right)^{3}} d s \\
& (8,4)=\frac{D_{\varphi}}{R_{j}} \int_{0}^{b} \frac{\theta^{(i)} \theta^{(j)}}{\left(R_{i}+s\right)^{3}} d s \\
& (8,7)=\frac{D_{\varphi}}{R_{j}} \int_{0}^{b} \frac{v^{(j)} \theta^{(j)}}{\left(R_{i}+s\right)^{3}} d s \\
& (8,8)=\frac{D_{\varphi}}{R_{j}} \int_{0}^{b} \frac{\theta^{(j)} \theta^{(j)}}{\left(R_{i}+s\right)^{3}} d s
\end{aligned}
$$

b) $\left[\boldsymbol{K}_{2}{ }^{p l}\right]$ マトリクス

$(i, j)=0$ (次に示す以外のマトリクス成分)

$$
\begin{aligned}
& (1,1)=-\frac{F_{\varphi}}{R_{i}} \int_{0}^{b} \frac{w^{(i)} w^{(i)}}{R_{i}+s} d s \\
& (1,5)=-\frac{F_{\varphi}}{R_{i}} \int_{0}^{b} \frac{w^{(j)} w^{(i)}}{R_{i}+s} d s \\
& (2,2)=-\frac{F_{k}}{R_{i}} \int_{0}^{b} \frac{u^{(i)} u^{(i)}}{R_{i}+s} d s \\
& (2,6)=-\frac{F_{k}}{R_{i}} \int_{0}^{b} \frac{u^{(j)} u^{(i)}}{R_{i}+s} d s \\
& (3,3)=-\frac{4 D_{k}}{R_{i}} \int_{0}^{b} \frac{v^{(i)} v^{(i)}}{\left(R_{i}+s\right)^{3}} d s+\frac{D_{\varphi}+4 D_{k}}{R_{i}}
\end{aligned}
$$

$$
\begin{aligned}
& -\left\{\int_{0}^{b} \frac{\dot{v}^{(i)} v^{(i)}}{\left(R_{i}+s\right)^{2}} d s+\int_{0}^{b} \frac{v^{(i)} \dot{v}^{(i)}}{\left(R_{i}+s\right)^{2}} d s\right\} \\
& +\frac{\nu_{r} D_{\varphi}}{R_{i}} \int_{0}^{b} \frac{\ddot{v}^{(i)} v^{(i)}}{R_{i}+s} d s-\frac{4 D_{k}}{R_{i}} \int_{0}^{b} \frac{\dot{v}^{(i)} \dot{v}^{(i)}}{R_{i}+s} d s \\
& +\frac{\nu_{\varphi} D_{r}}{R_{i}} \int_{0}^{b} \frac{v^{(i)} \ddot{v}^{(i)}}{R_{i}+s} d s
\end{aligned}
$$$$
(3,4)=-\frac{4 D_{k}}{R_{i}} \int_{0}^{b} \frac{\theta^{(i)} v^{(i)}}{\left(R_{i}+s\right)^{3}} d s+\frac{D_{\varphi}+4 D_{k}}{R_{i}}
$$$$
\cdot\left\{\int_{0}^{b} \frac{\dot{\theta}(i) v^{(i)}}{\left(R_{i}+s\right)^{2}} d s+\int_{0}^{b} \frac{\theta^{(i)} \dot{v}^{(i)}}{\left(R_{i}+s\right)^{2}} d s\right\}
$$$$
+\frac{\nu_{r} D_{\varphi}}{R_{i}} \int_{0}^{b} \frac{\ddot{\theta}^{(i)} v^{(i)}}{R_{i}+s} d s-\frac{4 D_{k}}{R_{i}} \int_{0}^{b} \frac{\dot{\theta}^{(i)} \dot{v}^{(i)}}{R_{i}+s} d s
$$$$
+\frac{\nu_{\varphi} D_{r}}{R_{i}} \int_{0}^{b} \frac{\theta^{(i)} \ddot{v}^{(i)}}{R_{i}+s} d s
$$$$
(3,7)=-\frac{4 D_{k}}{R_{i}} \int_{0}^{b} \frac{v^{(j)} v^{(i)}}{\left(R_{i}+s\right)^{3}} d s+\frac{D_{\varphi}+4 D_{k}}{R_{i}}
$$$$
\cdot\left\{\int_{0}^{b} \frac{\dot{v}^{(j)} v^{(i)}}{\left(R_{i}+s\right)^{2}} d s+\int_{0}^{b} \frac{v^{(j)} \dot{v}^{(i)}}{\left(R_{i}+s\right)^{2}} d s\right\}
$$$$
+\frac{\nu_{r} D_{\varphi}}{R_{i}} \int_{0}^{b} \frac{\ddot{v}^{(j)} v^{(i)}}{R_{i}+s} d s-\frac{4 D_{k}}{R_{i}} \int_{0}^{b} \frac{\dot{v}^{(j)} \dot{v}^{(i)}}{R_{i}+s} d s
$$$$
+\frac{\nu_{\varphi} D_{r}}{R_{i}} \int_{0}^{b} \frac{v^{(j)} \ddot{v}^{(i)}}{R_{i}+s} d s
$$$$
(3,8)=-\frac{4 D_{k}}{R_{i}} \int_{0}^{b} \frac{\theta^{(j)} v^{(i)}}{\left(R_{i}+s\right)^{3}} d s+\frac{D_{\varphi}+4 D_{k}}{R_{i}}
$$$$
\cdot\left\{\int_{0}^{b} \frac{\dot{\theta}^{(j)} v^{(i)}}{\left(R_{i}+s\right)^{2}} d s+\int_{0}^{b} \frac{\theta^{(j)} \dot{v}^{(i)}}{\left(R_{i}+s\right)^{2}} d s\right\}
$$$$
+\frac{\nu_{r} D_{\varphi}}{R_{i}} \int_{0}^{b} \frac{\ddot{\theta}^{(j)} v^{(i)}}{R_{i}+s} d s-\frac{4 D_{k}}{R_{i}} \int_{0}^{b} \frac{\dot{\theta}^{(j)} \dot{v}^{(i)}}{R_{i}+s} d s
$$$$
+\frac{\nu_{\varphi} D_{r}}{R_{i}} \int_{0}^{b} \frac{\theta^{(j)} \ddot{v}^{(i)}}{R_{i}+s} d s
$$

$$
\begin{aligned}
(4,3) & =-\frac{4 D_{k}}{R_{i}} \int_{0}^{b} \frac{v^{(i)} \theta^{(i)}}{\left(R_{i}+s\right)^{3}} d s+\frac{D_{\varphi}+4 D_{k}}{R_{i}} \\
& \cdot\left\{\int_{0}^{b} \frac{\dot{v}^{(i)} \theta^{(i)}}{\left(R_{i}+s\right)^{2}} d s+\int_{0}^{b} \frac{v^{(i)} \dot{\theta}^{(i)}}{\left(R_{i}+s\right)^{2}} d s\right\} \\
& +\frac{\nu_{r} D_{\varphi}}{R_{i}} \int_{0}^{b} \frac{\ddot{v}^{(i)} \theta^{(i)}}{R_{i}+s} d s-\frac{4 D_{k}}{R_{i}} \int_{0}^{b} \frac{\dot{v}^{(i)} \dot{\theta}^{(i)}}{R_{i}+s} d s \\
& +\frac{\nu_{\varphi} D_{r}}{R_{i}} \int_{0}^{b} \frac{v^{(i)} \ddot{\theta}^{(i)}}{R_{i}+s} d s
\end{aligned}
$$$$
(4,4)=-\frac{4 D_{k}}{R_{i}} \int_{0}^{b} \frac{\theta^{(i)} \theta^{(i)}}{\left(R_{i}+s\right)^{3}} d s+\frac{D_{\varphi}+4 D_{k}}{R_{i}}
$$$$
\cdot\left\{\int_{0}^{b} \frac{\dot{\theta}^{(i)} \theta^{(i)}}{\left(R_{i}+s\right)^{2}} d s+\int_{0}^{b} \frac{\theta^{(i)} \dot{\theta}^{(i)}}{\left(R_{i}+s\right)^{2}} d s\right\}
$$$$
+\frac{\nu_{r} D_{\varphi}}{R_{i}} \int_{0}^{b} \frac{\ddot{\theta}^{(i)} \theta^{(i)}}{R_{i}+s} d s-\frac{4 D_{k}}{R_{i}} \int_{0}^{b} \frac{\dot{\theta}^{(i)} \dot{\theta}(i)}{R_{i}+s} d s
$$$$
+\frac{\nu_{\varphi} D_{r}}{R_{i}} \int_{0}^{b} \frac{\theta^{(i)} \ddot{\theta}^{(i)}}{R_{i}+s} d s
$$

$$
\begin{aligned}
(4,7) & =-\frac{4 D_{k}}{R_{i}} \int_{0}^{b} \frac{v^{(j)} \theta^{(i)}}{\left(R_{i}+s\right)^{3}} d s+\frac{D_{\varphi}+4 D_{k}}{R_{i}} \\
& \cdot\left\{\int_{0}^{b} \frac{\dot{v}^{(j)} \theta^{(i)}}{\left(R_{i}+s\right)^{2}} d s+\int_{0}^{b} \frac{v^{(j) \dot{\theta}(i)}}{\left(R_{i}+s\right)^{2}} d s\right\} \\
& +\frac{\nu_{r} D_{\varphi}}{R_{i}} \int_{0}^{b} \frac{\ddot{v}^{(j)} \theta^{(i)}}{R_{i}+s} d s-\frac{4 D_{k}}{R_{i}} \int_{0}^{b} \frac{\dot{v}^{(j)} \dot{\theta}^{(i)}}{R_{i}+s} d s
\end{aligned}
$$




$$
\begin{aligned}
& +\frac{\nu_{\varphi} D_{r}}{R_{i}} \int_{0}^{b} \frac{v^{(j)} \ddot{\theta}^{(i)}}{R_{i}+s} d s \\
& (4,8)=-\frac{4 D_{k}}{R_{i}} \int_{0}^{b} \frac{\theta^{(j)} \theta^{(i)}}{\left(R_{i}+s\right)^{3}} d s+\frac{D_{\varphi}+4 D_{k}}{R_{i}} \\
& \text { - }\left\{\int_{0}^{b} \frac{\dot{\theta}(j) \theta^{(i)}}{\left(R_{i}+s\right)^{2}} d s+\int_{0}^{b} \frac{\theta^{(j)} \dot{\theta}(i)}{\left(R_{i}+s\right)^{2}} d s\right\} \\
& +\frac{\nu_{r} D_{\varphi}}{R_{i}} \int_{0}^{b} \frac{\ddot{\theta}^{(j)} \theta^{(i)}}{R_{i}+s} d s-\frac{4 D_{k}}{R_{i}} \int_{0}^{b} \frac{\dot{\theta}^{(j)} \dot{\theta}^{(i)}}{R_{i}+s} d s \\
& +\frac{\nu_{\varphi} D_{r}}{R_{i}} \int_{0}^{b} \frac{\theta^{(j)} \ddot{\theta}^{(i)}}{R_{i}+s} d s \\
& (5,1)=-\frac{F_{\varphi}}{R_{j}} \int_{0}^{b} \frac{w^{(i)} w^{(j)}}{R_{i}+s} d s \\
& (5,5)=-\frac{F_{\varphi}}{R_{j}} \int_{0}^{b} \frac{w^{(j)} w^{(j)}}{R_{i}+s} d s \\
& (6,2)=-\frac{F_{k}}{R_{j}} \int_{0}^{b} \frac{u^{(i)} u^{(j)}}{R_{i}+s} d s \\
& (6,6)=-\frac{F_{k}}{R_{j}} \int_{0}^{b} \frac{u^{(j)} u^{(j)}}{R_{i}+s} d s \\
& (7,3)=-\frac{4 D_{k}}{R_{j}} \int_{0}^{b} \frac{v^{(i)} v^{(j)}}{\left(R_{i}+s\right)^{3}} d s+\frac{D_{\varphi}+4 D_{k}}{R_{j}} \\
& \cdot\left\{\int_{0}^{b} \frac{\dot{v}^{(i)} v^{(j)}}{\left(R_{i}+s\right)^{2}} d s+\int_{0}^{b} \frac{v^{(i)} \dot{v}^{(j)}}{\left(R_{i}+s\right)^{2}} d s\right\} \\
& +\frac{\nu_{r} D_{\varphi}}{R_{j}} \int_{0}^{b} \frac{\ddot{v}^{(i)} v^{(j)}}{R_{i}+s} d s-\frac{4 D_{k}}{R_{j}} \int_{0}^{b} \frac{\dot{v}^{(i)} \dot{v}^{(j)}}{R_{i}+s} d s \\
& +\frac{\nu_{\varphi} D_{r}}{R_{j}} \int_{0}^{b} \frac{v^{(i)} \ddot{v}^{(j)}}{R_{i}+s} d s \\
& (7,4)=-\frac{4 D_{k}}{R_{j}} \int_{0}^{b} \frac{\theta^{(i)} v^{(j)}}{\left(R_{i}+s\right)^{3}} d s+\frac{D_{\varphi}+4 D_{k}}{R_{j}} \\
& \cdot\left\{\int_{0}^{b} \frac{\dot{\theta}(i) v^{(j)}}{\left(R_{i}+s\right)^{2}} d s+\int_{0}^{b} \frac{\theta^{(i)} \dot{v}^{(j)}}{\left(R_{i}+s\right)^{2}} d s\right\} \\
& +\frac{\nu_{r} D_{\varphi}}{R_{j}} \int_{0}^{b} \frac{\ddot{\theta}^{(i)} v^{(j)}}{R_{i}+s} d s-\frac{4 D_{k}}{R_{j}} \int_{0}^{b} \frac{\dot{\theta}^{(i)} \dot{v}^{(j)}}{R_{i}+s} d s \\
& +\frac{\nu_{\varphi} D_{r}}{R_{j}} \int_{0}^{b} \frac{\theta^{(i)} \ddot{v}^{(j)}}{R_{i}+s} d s \\
& (7,7)=-\frac{4 D_{k}}{R_{j}} \int_{0}^{b} \frac{v^{(j)} v^{(j)}}{\left(R_{i}+s\right)^{3}} d s+\frac{D_{\varphi}+4 D_{k}}{R_{j}} \\
& \cdot\left\{\int_{0}^{b} \frac{\dot{v}^{(j)} v^{(j)}}{\left(R_{i}+s\right)^{2}} d s+\int_{0}^{b} \frac{v^{(j)} \dot{v}^{(j)}}{\left(R_{i}+s\right)^{2}} d s\right\} \\
& +\frac{\nu_{r} D_{\varphi}}{R_{j}} \int_{0}^{b} \frac{\ddot{v}^{(j)} v^{(j)}}{R_{i}+s} d s-\frac{4 D_{k}}{R_{j}} \int_{0}^{b} \frac{\dot{v}^{(j)} \dot{v}^{(j)}}{R_{i}+s} d s \\
& +\frac{\nu_{\varphi} D_{r}}{R_{j}} \int_{0}^{b} \frac{v^{(j)} \ddot{v}^{(j)}}{R_{i}+s} d s \\
& (7,8)=-\frac{4 D_{k}}{R_{j}} \int_{0}^{b} \frac{\theta^{(j)} v^{(j)}}{\left(R_{i}+s\right)^{3}} d s+\frac{D_{\varphi}+4 D_{k}}{R_{j}} \\
& \cdot\left\{\int_{0}^{b} \frac{\dot{\theta}^{(j)} v^{(j)}}{\left(R_{i}+s\right)^{2}} d s+\int_{0}^{b} \frac{\theta^{(j)} \dot{v}^{(j)}}{\left(R_{i}+s\right)^{2}} d s\right\} \\
& +\frac{\nu_{r} D_{\varphi}}{R_{j}} \int_{0}^{b} \frac{\ddot{\theta}^{(j)} v^{(j)}}{R_{i}+s} d s-\frac{4 D_{k}}{R_{j}} \int_{0}^{b} \frac{\dot{\theta}(j) \dot{v}^{(j)}}{R_{i}+s} d s \\
& +\frac{\nu_{\varphi} D_{r}}{R_{j}} \int_{0}^{b} \frac{\theta^{(j)} \ddot{v}^{(j)}}{R_{i}+s} d s \\
& (8,3)=-\frac{4 D_{k}}{R_{j}} \int_{0}^{b} \frac{v^{(i)} \theta^{(j)}}{\left(R_{i}+s\right)^{3}} d s+\frac{D_{\varphi}+4 D_{k}}{R_{j}} \\
& \begin{array}{l}
\cdot\left\{\int_{0}^{b} \frac{\dot{v}^{(i)} \theta^{(j)}}{\left(R_{i}+s\right)^{2}} d s+\int_{0}^{b} \frac{v^{(i)} \dot{\theta}(j)}{\left(R_{i}+s\right)^{2}} d s\right\} \\
+\frac{\nu_{r} D_{\varphi}}{R_{j}} \int_{0}^{b} \frac{\ddot{v}^{(i)} \theta^{(j)}}{R_{i}+s} d s-\frac{4 D_{k}}{R_{j}} \int_{0}^{b} \frac{\dot{v}^{(i)} \dot{\theta}(j)}{R_{i}+s} d s \\
+\frac{\nu_{\varphi} D_{r}}{R_{j}} \int_{0}^{b} \frac{v^{(i)} \ddot{\theta}^{(j)}}{R_{i}+s} d s
\end{array} \\
& (8,4)=-\frac{4 D_{k}}{R_{j}} \int_{0}^{b} \frac{\theta^{(i)} \theta^{(j)}}{\left(R_{i}+s\right)^{3}} d s+\frac{D_{\varphi}+4 D_{k}}{R_{j}} \\
& \cdot\left\{\int_{0}^{b} \frac{\dot{\theta}(i) \theta^{(j)}}{\left(R_{i}+s\right)^{2}} d s+\int_{0}^{b} \frac{\theta^{(i)} \dot{j}^{(j)}}{\left(R_{i}+s\right)^{2}} d s\right\} \\
& +\frac{\nu_{r} D_{\varphi}}{R_{j}} \int_{0}^{b} \frac{\ddot{\theta}^{(i)} \theta^{(j)}}{R_{i}+s} d s-\frac{4 D_{k}}{R_{j}} \int_{0}^{b} \frac{\dot{\theta}(i) \dot{\theta}(j)}{R_{i}+s} d s \\
& +\frac{\nu_{\varphi} D_{r}}{R_{j}} \int_{0}^{b} \frac{\theta^{(i)} \ddot{\theta}^{(j)}}{R_{i}+s} d s \\
& (8,7)=-\frac{4 D_{k}}{R_{j}} \int_{0}^{b} \frac{v^{(j)} \theta^{(j)}}{\left(R_{i}+s\right)^{3}} d s+\frac{D_{\varphi}+4 D_{k}}{R_{j}} \\
& \cdot\left\{\int_{0}^{b} \frac{\dot{v}^{(j)} \theta^{(j)}}{\left(R_{i}+s\right)^{2}} d s+\int_{0}^{b} \frac{v^{(j)} \dot{\theta}^{(j)}}{\left(R_{i}+s\right)^{2}} d s\right\} \\
& +\frac{\nu_{r} D_{\varphi}}{R_{j}} \int_{0}^{b} \frac{\ddot{v}^{(i)} \theta^{(j)}}{R_{i}+s} d s-\frac{4 D_{k}}{R_{j}} \int_{0}^{b} \frac{\dot{v}^{(j)} \dot{\theta}(j)}{R_{i}+s} d s \\
& +\frac{\nu_{\varphi} D_{r}}{R_{j}} \int_{0}^{b} \frac{v^{(j)} \ddot{\theta}^{(j)}}{R_{i}+s} d s \\
& (8,8)=-\frac{4 D_{k}}{R_{j}} \int_{0}^{b} \frac{\theta^{(j)} \theta^{(j)}}{\left(R_{i}+s\right)^{3}} d s+\frac{D_{\varphi}+4 D_{k}}{R_{j}} \\
& \cdot\left\{\int_{0}^{b} \frac{\dot{\theta}^{(j)} \theta^{(j)}}{\left(R_{i}+s\right)^{2}} d s+\int_{0}^{b} \frac{\theta^{(j)} \dot{\theta}(j)}{\left(R_{i}+s\right)^{2}} d s\right\} \\
& +\frac{\nu_{r} D_{\varphi}}{R_{j}} \int_{0}^{b} \frac{\ddot{\theta}^{(j)} \theta^{(j)}}{R_{i}+s} d s-\frac{4 D_{k}}{R_{j}} \int_{0}^{b} \frac{\dot{\beta}(j) \dot{\theta}(j)}{R_{i}+s} d s \\
& +\frac{\nu_{\varphi} D_{r}}{R_{j}} \int_{0}^{b} \frac{\theta^{(j)} \ddot{\theta}(j)}{R_{i}+s} d s \\
& (1,2)=-\frac{F_{\varphi}+F_{k}}{R_{i}} \int_{0}^{b} \frac{u^{(i)} w^{(i)}}{R_{i}+s} d s \\
& -\frac{\nu_{r} F_{\varphi}}{R_{i}} \int_{0}^{b} \dot{u}^{(i)} w^{(i)} d s+\frac{F_{k}}{R_{i}} \int_{0}^{b} u^{(i)} \dot{w}^{(i)} d s \\
& (1,6)=-\frac{F_{\varphi}+F_{k}}{R_{i}} \int_{0}^{b} \frac{u^{(j)} w^{(i)}}{R_{i}+s} d s \\
& -\frac{\nu_{r} F_{\varphi}}{R_{i}} \int_{0}^{b} \dot{u}^{(j)} w^{(i)} d s+\frac{F_{k}}{R_{i}} \int_{0}^{b} u^{(j)} \dot{w}^{(i)} d s \\
& (2,1)=\frac{F_{\varphi}+F_{k}}{R_{i}} \int_{0}^{b} \frac{w^{(i)} u^{(i)}}{R_{i}+s} d s \\
& +\frac{\nu_{\varphi} F_{r}}{R_{i}} \int_{0}^{b} w^{(i)} \dot{u}^{(i)} d s-\frac{F_{k}}{R_{i}} \int_{0}^{b} \dot{w}^{(i)} u^{(i)} d s \\
& (2,5)=\frac{F_{\varphi}+F_{k}}{R_{i}} \int_{0}^{b} \frac{w^{(j)} u^{(i)}}{R_{i}+s} d s \\
& +\frac{\nu_{\varphi} F_{r}}{R_{i}} \int_{0}^{b} w^{(j)} \dot{u}^{(i)} d s-\frac{F_{k}}{R_{i}} \int_{0}^{b} \dot{w}^{(j)} u^{(i)} d s \\
& (5,2)=-\frac{F_{\varphi}+F_{k}}{R_{j}} \int_{0}^{b} \frac{u^{(i)} w^{(j)}}{R_{i}+s} d s \\
& -\frac{\nu_{r} F_{\varphi}}{R_{j}} \int_{0}^{b} \dot{u}^{(i)} w^{(j)} d s+\frac{F_{k}}{R_{j}} \int_{0}^{b} u^{(i)} \dot{w}^{(j)} d s
\end{aligned}
$$




$$
\begin{aligned}
(5,6) & =-\frac{F_{\varphi}+F_{k}}{R_{j}} \int_{0}^{b} \frac{u^{(j)} w^{(j)}}{R_{i}+s} d s \\
& -\frac{\nu_{r} F_{\varphi}}{R_{j}} \int_{0}^{b} \dot{u}^{(j)} w^{(j)} d s+\frac{F_{k}}{R_{j}} \int_{0}^{b} u^{(j)} \dot{w}^{(j)} d s \\
(6,1) & =\frac{F_{\varphi}+F_{k}}{R_{j}} \int_{0}^{b} \frac{w^{(i)} u^{(j)}}{R_{i}+s} d s \\
& +\frac{\nu_{\varphi} F_{r}}{R_{j}} \int_{0}^{b} w^{(i)} \dot{u}^{(j)} d s-\frac{F_{k}}{R_{j}} \int_{0}^{b} \dot{w}^{(i)} u^{(j)} d s \\
(6,5) & =\frac{F_{\varphi}+F_{k}}{R_{j}} \int_{0}^{b} \frac{w^{(j)} u^{(j)}}{R_{i}+s} d s \\
& +\frac{\nu_{\varphi} F_{r}}{R_{j}} \int_{0}^{b} w^{(j)} \dot{u}^{(j)} d s-\frac{F_{k}}{R_{j}} \int_{0}^{b} \dot{w}^{(j)} u^{(j)} d s
\end{aligned}
$$

d) $\left[K_{4}^{p l}\right]$ マトリクス

$(i, j)=0$ (次に示す以外のマトリクス成分)

$$
\begin{aligned}
& (1,1)=\frac{F_{k}}{R_{i}}\left\{\int_{0}^{b} \frac{w^{(i)} w^{(i)}}{R_{i}+s} d s-\int_{0}^{b} \dot{w}^{(i)} w^{(i)} d s\right. \\
& \left.-\int_{0}^{b} w^{(i)} \dot{w}^{(i)} d s+\int_{0}^{b} \dot{w}^{(i)} \dot{w}^{(i)}\left(R_{i}+s\right) d s\right\} \\
& (1,5)=\frac{F_{k}}{R_{i}}\left\{\int_{0}^{b} \frac{w^{(j)} w^{(i)}}{R_{i}+s} d s-\int_{0}^{b} \dot{w}^{(j)} w^{(i)} d s\right. \\
& \left.-\int_{0}^{b} w^{(j)} \dot{w}^{(i)} d s+\int_{0}^{b} \dot{w}^{(j)} \dot{w}^{(i)}\left(R_{i}+s\right) d s\right\} \\
& (2,2)=\frac{F_{\varphi}}{R_{i}} \int_{0}^{b} \frac{u^{(i)} u^{(i)}}{R_{i}+s} d s+\frac{\nu_{r} F_{\varphi}}{R_{i}} \int_{0}^{b} \dot{u}^{(i)} u^{(i)} d s \\
& +\frac{\nu_{\varphi} F_{r}}{R_{i}} \int_{0}^{b} u^{(i)} \dot{u}^{(i)} d s+\frac{F_{r}}{R_{i}} \\
& \text { - } \int_{0}^{b} \dot{u}^{(i)} \dot{u}^{(i)}\left(R_{i}+s\right) d s \\
& (2,6)=\frac{F_{\varphi}}{R_{i}} \int_{0}^{b} \frac{u^{(j)} u^{(i)}}{R_{i}+s} d s+\frac{\nu_{r} F_{\varphi}}{R_{i}} \int_{0}^{b} \dot{u}^{(j)} u^{(i)} d s \\
& +\frac{\nu_{\varphi} F_{r}}{R_{i}} \int_{0}^{b} u^{(j)} \dot{u}^{(i)} d s+\frac{F_{r}}{R_{i}} \\
& \cdot \int_{0}^{b} \dot{u}^{(j)} \dot{u}^{(i)}\left(R_{i}+s\right) d s \\
& (3,3)=\frac{D_{\varphi}}{R_{i}} \int_{0}^{b} \frac{\dot{v}^{(i)} \dot{v}^{(i)}}{R_{i}+s} d s+\frac{\nu_{r} D_{\varphi}}{R_{i}} \int_{0}^{b} \ddot{v}^{(i)} \dot{v}^{(i)} d s \\
& +\frac{\nu_{\varphi} D_{r}}{R_{i}} \int_{0}^{b} \dot{v}^{(i)} \ddot{v}^{(i)} d s+\frac{D_{r}}{R_{i}} \\
& \cdot \int_{0}^{b} \ddot{v}^{(i)} \ddot{v}^{(i)}\left(R_{i}+s\right) d s \\
& (3,4)=\frac{D_{\varphi}}{R_{i}} \int_{0}^{b} \frac{\dot{\theta}(i) \dot{v}^{(i)}}{R_{i}+s} d s+\frac{\nu_{r} D_{\varphi}}{R_{i}} \int_{0}^{b} \ddot{\theta}^{(i)} \dot{v}^{(i)} d s \\
& +\frac{\nu_{\varphi} D_{r}}{R_{i}} \int_{0}^{b} \dot{\theta}^{(i)} \ddot{v}^{(i)} d s+\frac{D_{r}}{R_{i}} \\
& \cdot \int_{0}^{b} \ddot{\theta}^{(i)} \ddot{v}^{(i)}\left(R_{i}+s\right) d s \\
& (3,7)=\frac{D_{\varphi}}{R_{i}} \int_{0}^{b} \frac{\dot{v}^{(j)} \dot{v}^{(i)}}{R_{i}+s} d s+\frac{\nu_{r} D_{\varphi}}{R_{i}} \int_{0}^{b} \ddot{v}^{(j)} \dot{v}^{(i)} d s \\
& +\frac{\nu_{\varphi} D_{r}}{R_{i}} \int_{0}^{b} \dot{v}^{(j)} \ddot{v}^{(i)} d s+\frac{D_{r}}{R_{i}} \\
& \cdot \int_{0}^{b} \ddot{v}^{(j)} \ddot{v}^{(i)}\left(R_{i}+s\right) d s
\end{aligned}
$$

$(3,8)=\frac{D_{\varphi}}{R_{i}} \int_{0}^{b} \frac{\dot{\theta}^{(j)} \dot{v}^{(i)}}{R_{i}+s} d s+\frac{\nu_{r} D_{\varphi}}{R_{i}} \int_{0}^{b} \ddot{\theta}(j) \dot{v}^{(i)} d s$ $+\frac{\nu_{\varphi} D_{r}}{R_{i}} \int_{0}^{b} \dot{\theta}(j) \ddot{v}^{(i)} d s+\frac{D_{r}}{R_{i}}$

- $\int_{0}^{b} \ddot{\theta}^{(j)} \ddot{v}^{(i)}\left(R_{i}+s\right) d s$

$(4,3)=\frac{D_{\varphi}}{R_{i}} \int_{0}^{b} \frac{\dot{v}^{(i)} \dot{\theta}(i)}{R_{i}+s} d s+\frac{\nu_{r} D_{\varphi}}{R_{i}} \int_{0}^{b} \ddot{v}^{(i)} \dot{\dot{\theta}(i)} d s$ $+\frac{\nu_{\varphi} D_{r}}{R_{i}} \int_{0}^{b} \dot{v}^{(i)} \ddot{\theta}^{(i)} d s+\frac{D_{r}}{R_{i}}$

$\cdot \int_{0}^{b} \ddot{v}^{(i)} \ddot{\theta}^{(i)}\left(R_{i}+s\right) d s$

$(4,4)=\frac{D_{\varphi}}{R_{i}} \int_{0}^{b} \frac{\dot{\theta}(i) \dot{\theta}(i)}{R_{i}+s} d s+\frac{\nu_{r} D_{\varphi}}{R_{i}} \int_{0}^{b} \ddot{\theta}^{(i)} \dot{\theta}^{(i)} d s$ $+\frac{\nu_{\varphi} D_{r}}{R_{i}} \int_{0}^{b} \dot{\theta}^{(i)} \ddot{\theta}^{(i)} d s+\frac{D_{r}}{R_{i}}$ - $\int_{0}^{b} \ddot{\theta}^{(i)} \ddot{\theta}^{(i)}\left(R_{i}+s\right) d s$

$(4,7)=\frac{D_{\varphi}}{R_{i}} \int_{0}^{b} \frac{\dot{v}^{(j)} \dot{\theta}(i)}{R_{i}+s} d s+\frac{\nu_{r} D_{\varphi}}{R_{i}} \int_{0}^{b} \ddot{v}^{(j) \dot{\theta}(i)} d s$ $+\frac{\nu_{\varphi} D_{r}}{R_{i}} \int_{0}^{b} \dot{v}^{(j)} \ddot{\theta}^{(i)} d s+\frac{D_{r}}{R_{i}}$

- $\int_{0}^{b} \ddot{v}^{(j)} \ddot{\theta}^{(i)}\left(R_{i}+s\right) d s$

$(4,8)=\frac{D_{\varphi}}{R_{i}} \int_{0}^{b} \frac{\dot{\theta}(j) \dot{\theta}(i)}{R_{i}+s} d s+\frac{\nu_{r} D_{\varphi}}{R_{i}} \int_{0}^{b} \ddot{\theta}^{(j)} \dot{\theta}^{(i)} d s$ $+\frac{\nu_{\varphi} D_{r}}{R_{i}} \int_{0}^{b} \dot{\theta}^{(j)} \ddot{\theta}^{(i)} d s+\frac{D_{r}}{R_{i}}$ - $\int_{0}^{b} \ddot{\theta}(j) \ddot{\theta}^{(i)}\left(R_{i}+s\right) d s$

$(5,1)=\frac{F_{k}}{R_{j}}\left\{\int_{0}^{b} \frac{w^{(i)} w^{(j)}}{R_{i}+s} d s-\int_{0}^{b} \dot{w}^{(i)} w^{(j)} d s\right.$ $\left.-\int_{0}^{b} w^{(i)} \dot{w}^{(j)} d s+\int_{0}^{b} \dot{w}^{(i)} \dot{w}^{(j)}\left(R_{i}+s\right) d s\right\}$

$(5,5)=\frac{F_{k}}{R_{j}}\left\{\int_{0}^{b} \frac{w^{(j)} w^{(j)}}{R_{i}+s} d s-\int_{0}^{b} \dot{w}^{(j)} w^{(j)} d s\right.$ $\left.-\int_{0}^{b} w^{(j)} \dot{w}^{(j)} d s+\int_{0}^{b} \dot{w}^{(j)} \dot{w}^{(j)}\left(R_{i}+s\right) d s\right\}$

$(6,2)=\frac{F_{\varphi}}{R_{j}} \int_{0}^{b} \frac{u^{(i)} u^{(j)}}{R_{i}+s} d s+\frac{\nu_{r} F_{\varphi}}{R_{j}} \int_{0}^{b} \dot{u}^{(i)} u^{(j)} d s$ $+\frac{\nu_{\varphi} F_{r}}{R_{j}} \int_{0}^{b} u^{(i)} \dot{u}^{(j)} d s+\frac{F_{r}}{R_{j}}$

- $\int_{0}^{b} \dot{u}^{(i)} \dot{u}^{(j)}\left(R_{i}+s\right) d s$

$(6,6)=\frac{F_{\varphi}}{R_{j}} \int_{0}^{b} \frac{u^{(j)} u^{(j)}}{R_{i}+s} d s+\frac{\nu_{r} F_{\varphi}}{R_{j}} \int_{0}^{b} \dot{u}^{(j)} u^{(j)} d s$ $+\frac{\nu_{\varphi} F_{r}}{R_{j}} \int_{0}^{b} u^{(j)} \dot{u}^{(j)} d s+\frac{F_{r}}{R_{j}}$ $\cdot \int_{0}^{b} \dot{u}^{(j)} \dot{u}^{(j)}\left(R_{i}+s\right) d s$

$(7,3)=\frac{D_{\varphi}}{R_{j}} \int_{0}^{b} \frac{\dot{v}^{(i)} \dot{v}^{(j)}}{R_{i}+s} d s+\frac{\nu_{r} D_{\varphi}}{R_{j}} \int_{0}^{b} \ddot{v}^{(i)} \dot{v}^{(j)} d s$ 


$$
\begin{aligned}
& +\frac{\nu_{\varphi} D_{r}}{R_{j}} \int_{0}^{b} \dot{v}^{(i)} \ddot{v}^{(j)} d s+\frac{D_{r}}{R_{j}} \\
& -\int_{0}^{b} \ddot{v}^{(i)} \ddot{v}^{(j)}\left(R_{i}+s\right) d s
\end{aligned}
$$

$(7,4)=\frac{D_{\varphi}}{R_{j}} \int_{0}^{b} \frac{\dot{\theta}^{(i)} \dot{v}^{(j)}}{R_{i}+s} d s+\frac{\nu_{r} D_{\varphi}}{R_{j}} \int_{0}^{b} \ddot{\theta}^{(i)} \dot{v}^{(j)} d s$ $+\frac{\nu_{\varphi} D_{r}}{R_{j}} \int_{0}^{b} \dot{\theta}^{(i)} \ddot{v}^{(j)} d s+\frac{D_{r}}{R_{j}}$ - $\int_{0}^{b} \ddot{\theta}^{(i)} \ddot{v}^{(j)}\left(R_{i}+s\right) d s$

$(7,7)=\frac{D_{\varphi}}{R_{j}} \int_{0}^{b} \frac{\dot{v}^{(i)} \dot{v}^{(j)}}{R_{i}+s} d s+\frac{\nu_{r} D_{\varphi}}{R_{j}} \int_{0}^{b} \ddot{v}^{(j)} \dot{v}^{(j)} d s$ $+\frac{\nu_{\varphi} D_{r}}{R_{j}} \int_{0}^{b} \dot{v}^{(j)} \ddot{v}^{(j)} d s+\frac{D_{r}}{R_{j}}$ - $\int_{0}^{b} \ddot{v}^{(j)} \ddot{v}^{(j)}\left(R_{i}+s\right) d s$

$(7,8)=\frac{D_{\varphi}}{R_{j}} \int_{0}^{b} \frac{\dot{\theta}^{(j)} \dot{v}^{(j)}}{R_{i}+s} d s+\frac{\nu_{r} D_{\varphi}}{R_{j}} \int_{0}^{b} \ddot{\theta}^{(j)} \dot{v}^{(j)} d s$ $+\frac{\nu_{\varphi} D_{r}}{R_{j}} \int_{0}^{b} \dot{\theta}^{(j)} \ddot{v}^{(j)} d s+\frac{D_{r}}{R_{j}}$ - $\int_{0}^{b} \ddot{\theta}^{(j)} \ddot{v}^{(j)}\left(R_{i}+s\right) d s$

$(8,3)=\frac{D_{\varphi}}{R_{j}} \int_{0}^{b} \frac{\dot{v}^{(i)} \dot{\theta}^{(j)}}{R_{i}+s} d s+\frac{\nu_{r} D_{\varphi}}{R_{j}} \int_{0}^{b} \ddot{v}^{(i)} \dot{\theta}^{(j)} d s$ $+\frac{\nu_{\varphi} D_{r}}{R_{j}} \int_{0}^{b} \dot{v}^{(i)\left(\ddot{\theta}^{j}\right)} d s+\frac{D_{r}}{R_{j}}$

- $\int_{0}^{b} \ddot{v}^{(i)} \ddot{\theta}^{(j)}\left(R_{i}+s\right) d s$

$(8,4)=\frac{D_{\varphi}}{R_{j}} \int_{0}^{b} \frac{\dot{\theta}^{(i)} \dot{\theta}^{(j)}}{R_{i}+s} d s+\frac{\nu_{r} D_{\varphi}}{R_{j}} \int_{0}^{b} \ddot{\theta}^{(i)} \dot{\theta}^{(j)} d s$ $+\frac{\nu_{\varphi} D_{r}}{R_{j}} \int_{0}^{b} \dot{\theta}^{(i)} \ddot{\theta}(j) d s+\frac{D_{r}}{R_{j}}$ - $\int_{0}^{b} \ddot{\theta}^{(i)} \ddot{\theta}^{(j)}\left(R_{i}+s\right) d s$

$(8,7)=\frac{D_{\varphi}}{R_{j}} \int_{0}^{b} \frac{\dot{v}^{(j)} \dot{\theta}^{(j)}}{R_{i}+s} d s+\frac{\nu_{r} D_{\varphi}}{R_{j}} \int_{0}^{b} \ddot{v}^{(j)} \dot{\theta}^{(j)} d s$ $+\frac{\nu_{\varphi} D_{r}}{R_{j}} \int_{0}^{b} \dot{v}^{(j)} \ddot{\theta}(j) d s+\frac{D_{r}}{R_{j}}$ - $\int_{0}^{b} \ddot{v}^{(j)} \ddot{\theta}^{(j)}\left(R_{i}+s\right) d s$

$(8,8)=\frac{D_{\varphi}}{R_{j}} \int_{0}^{b} \frac{\dot{\theta}^{(j)} \dot{\theta}^{(j)}}{R_{i}+s} d s+\frac{\nu_{r} D_{\varphi}}{R_{j}} \int_{0}^{b} \ddot{\theta}^{(j)} \dot{\theta}^{(j)} d s$ $+\frac{\nu_{\varphi} D_{r}}{R_{j}} \int_{0}^{b} \dot{\theta}^{(j)} \ddot{\theta}^{(j)} d s+\frac{D_{r}}{R_{j}}$ - $\int_{0}^{b} \ddot{\theta}^{(j)} \ddot{\theta}^{(j)}\left(R_{i}+s\right) d s$

以上のマトリクス成分は積分形で与えられているが, 実際には, 88 個の定積分に対して Newton-Cotes の 9 点公式程度のものを用いて数值積分すればよい。結果は 十分な精度でその値を求めることができる。

\section{（3）曲板要素の剛性マトリクスの誘導}

図一1 において点 $i, i^{\prime}, k, k^{\prime}$ で囲まれた要素を曲板 要素 $i k$ とよぶことにし, $\overparen{i i^{\prime}}, \widehat{k k^{\prime}}$ を節線 $i i^{\prime}$, 節線 $k k^{\prime}$ とよぶことにする。また初期曲率半径を $R_{i k}$, 要素の幅 を $h$ とする。

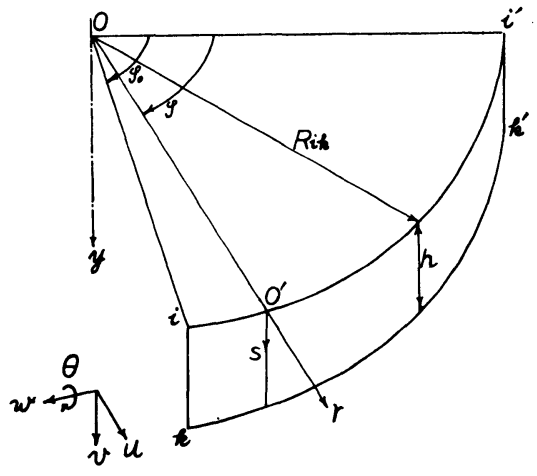

図一3 曲板 要素

図一3 に示すように，基準座標系ならびにその座標方 向の変位, 節線変位などはすべて扇形板要素の場合と同 じ記号で表わすことにし，局所座標系を $0^{\prime}-s$ とする。 曲板要素は等方性を有するものとし, 面内変形と面外 変形の間に相互の連成がないものとすれば, 次の手順で 曲板要素の剛性マトリクスを導くことができる。

曲板の $\varphi, y, r$ 軸方向の平衡方程式は, Donnell の理 論47)にしたがえば次の 3 式で表わされる。

$$
\begin{aligned}
& \frac{1}{R_{i k}} N_{\varphi}{ }^{\prime}+N_{\varphi y^{\circ}}+p_{\varphi}=0 \\
& \frac{1}{R_{i k}} N_{\varphi y}^{\prime}+N_{y}+p_{y}=0 \\
& \frac{1}{R_{i k}{ }^{2}} M_{\varphi}{ }^{\prime \prime}+\frac{2}{R_{i k}} N_{\varphi y^{\prime}}{ }^{\prime}+M_{y} \cdot{ }^{\cdot}-\frac{N_{\varphi}}{R_{i k}}+p_{r}=0
\end{aligned}
$$

ここで, ( ) $)^{\prime}=\partial(\quad) / \partial \varphi,(\quad)^{*}=\partial() / \partial y$ とし, $N_{\varphi}$, $N_{y}, N_{\varphi y}$ は応力, $M_{\varphi}, M_{y}, M_{\varphi y}$ は曲げおよびねじり モーメントであり， $p_{\varphi}, p_{y}, p_{r}$ はそれぞれ $\varphi, y, r$ 軸方 向の単位面積当り分布荷重である。面内および面外のひ ずみを $\varepsilon_{\varphi}, \varepsilon_{y}, r_{\varphi y}, \chi_{\varphi}, \chi_{y}, \chi_{\varphi}$ とすれば, 応力とひず みの関係は次式で表わされる。

$$
\begin{aligned}
& \left\{\begin{array}{l}
N_{\varphi} \\
N_{y} \\
N_{\varphi y}
\end{array}\right\}=\left[\begin{array}{ccc}
F & \nu F & 0 \\
\nu F & F & 0 \\
0 & 0 & \frac{1-\nu}{2} F
\end{array}\right]\left\{\begin{array}{l}
\varepsilon_{\varphi} \\
\varepsilon_{y} \\
r_{\varphi y}
\end{array}\right\} \ldots \ldots(12 \cdot \mathrm{a}) \\
& \left\{\begin{array}{l}
M_{\varphi} \\
M_{y} \\
M_{\varphi y}
\end{array}\right\}=\left[\begin{array}{ccc}
D & \nu D & 0 \\
\nu D & D & 0 \\
0 & 0 & \frac{1-\nu}{2} D
\end{array}\right]\left\{\begin{array}{l}
\chi_{\varphi} \\
\chi_{y} \\
2 \chi_{\varphi y}
\end{array}\right\} \ldots \ldots(12 \cdot \mathrm{b})
\end{aligned}
$$

ここで, $\nu$ はポアソン比, $t$ は板厚, $F, D$ は板の面 内剛性, 面外剛性であり, $F=\frac{E t}{1-\nu^{2}}, D=\frac{E t^{3}}{12\left(1-\nu^{2}\right)}$ と する。 
ひずみと変位の関係は次式で表示される。

$$
\begin{aligned}
& \varepsilon_{\varphi}=\frac{1}{R_{i k}} w^{\prime}+\frac{u}{R_{i k}} \\
& \varepsilon_{y}=v^{\circ} \\
& r_{\varphi y}=\frac{1}{R_{i k}} v^{\prime}+w \\
& \chi_{\varphi}=-\frac{1}{R_{i k}} u^{\prime \prime} \\
& \chi_{y}=-u^{\cdot} \cdot \\
& \chi_{\varphi y}=-\frac{1}{R_{i k}} u^{\prime}
\end{aligned}
$$

要素について变位関数を次のように仮定する。

$$
\begin{aligned}
w(\varphi, s) & =w^{(i)}(s) w_{i}(\varphi) \\
& +w^{(k)}(s) w_{k}(\varphi)
\end{aligned}
$$

$u(\varphi, s)=u^{(i)}(s) u_{i}(\varphi)+\theta^{(i)}(s) \theta_{i}(\varphi)$

$$
+u^{(k)}(s) u_{k}(\varphi)+\theta^{(k)}(s) \theta_{k}(\varphi) \cdots(14 \cdot \mathrm{b})
$$$$
v(\varphi, s)=v^{(i)}(s) v_{i}(\varphi)+v^{(k)}(s) v_{k}(\varphi)
$$
ただし，

$$
\begin{aligned}
& w^{(i)}(s)=v^{(i)}(s)=1-\frac{s}{h} \\
& w^{(k)}(s)=v^{(k)}(s)=\frac{s}{h} \ldots \\
& u^{(i)}(s)=1-\frac{3}{h^{2}} s^{2}+\frac{2}{h^{3}} s^{3} \ldots \\
& \theta^{(i)}(s)=-s+\frac{2}{h} s^{2}-\frac{1}{h^{2}} s^{3} \\
& u^{(k)}(s)=\frac{3}{h^{2}} s^{2}-\frac{2}{h^{3}} s^{3} \\
& \theta^{(k)}(s)=\frac{1}{h} s^{2}-\frac{1}{h^{2}} s^{3}
\end{aligned}
$$

式(11)の平衡方程式に対して，式(14)のように仮定され た変位関数を用いて, 重みつき残差法としての Galerkin 法を適用すれば，次の 8 式を導くことができる。

$$
\begin{aligned}
& \int_{0}^{h}\left(\frac{1}{R_{i k}} N_{\varphi}{ }^{\prime}+N_{\varphi y}{ }^{\circ}+p_{\varphi}\right) w^{(i)} d s=0 \quad \cdots(16 \cdot \mathrm{a}) \\
& \int_{0}^{h}\left(\frac{1}{R_{i k}} N_{\varphi}^{\prime}+N_{\varphi y^{\cdot}}+p_{\varphi}\right) w^{(k)} d s=0 \cdots \cdots(16 \cdot \mathrm{b}) \\
& \int_{0}^{h}\left(\frac{1}{R_{i k}} N_{\varphi y^{\prime}}+N_{y} \cdot+p_{y}\right) v^{(i)} d s=0 \cdots \cdots(16 \cdot \mathrm{c}) \\
& \int_{0}^{h}\left(\frac{1}{R_{i k}} N_{\varphi y^{\prime}}+N_{y}+p_{y}\right) v^{(k)} d s=0 \\
& \int_{0}^{h}\left(\frac{1}{R_{i k}{ }^{2}} M_{\varphi}^{\prime \prime}+\frac{2}{R_{i k}} M_{\varphi y^{\prime}}+M_{y} \cdot\right. \\
& \left.-\frac{N_{\varphi}}{R_{i k}}+p_{r}\right) u^{(i)} d s=0 \\
& \int_{0}^{h}\left(\frac{1}{R_{i k}{ }^{2}} M_{\varphi}^{\prime \prime}+\frac{2}{R_{i k}} M_{\varphi y^{\prime}} \cdot+M_{y} \cdot\right. \\
& \left.-\frac{N_{\varphi}}{R_{i k}}+p_{r}\right) u^{(k)} d s=0 \\
& \int_{0}^{h}\left(\frac{1}{R_{i k}{ }^{2}} M_{\varphi}^{\prime \prime}+\frac{2}{R_{i k}} M_{\varphi y^{\prime}} \cdot+M_{y} \cdot\right.
\end{aligned}
$$

$$
\begin{array}{r}
\left.-\frac{N_{\varphi}}{R_{i k}}+p_{r}\right) \theta^{(i)} d s=0 \quad \cdots \cdots \\
\int_{0}^{h}\left(\frac{1}{R_{i k}{ }^{2}} M_{\varphi}{ }^{\prime \prime}+\frac{2}{R_{i k}} M_{\varphi y^{\prime}}+M_{y} \cdot\right. \\
\left.-\frac{N_{\varphi}}{R_{i k}}+p_{r}\right) \theta^{(k)} d s=0 \quad \cdots \cdots
\end{array}
$$

式 (16) の $\partial^{2} / \partial s^{2}$ 項 および $\partial / \partial s$ 項を部分積分すれ ば, $w^{(i)}, w^{(k)}, u^{(i)}, u^{(k)}, v^{(i)}, v^{(k)}, \theta^{(i)}, \theta^{(k)}$ の定義 によって次式が導かれる。

$$
\begin{aligned}
& N_{\varphi y}{ }^{(i)}(\varphi)=-\int_{0}^{h}\left(\frac{1}{R_{i k}} N_{\varphi}{ }^{\prime} w^{(i)}-N_{\varphi y} \dot{w}^{(i)}\right. \\
& \left.+p_{\varphi} w^{(i)}\right) d s \\
& N_{\varphi y}{ }^{(k)}(\varphi)=-\int_{0}^{h}\left(\frac{1}{R_{i k}} N_{\varphi}^{\prime} w^{(k)}-N_{\varphi y} \dot{w}^{(k)}\right. \\
& \left.+p_{\varphi} w^{(k)}\right) d s \\
& N_{y}^{(i)}(\varphi)=-\int_{0}^{h}\left(\frac{1}{R_{i k}} N_{\varphi y^{\prime}} \gamma^{(i)}-N_{y} \dot{v}^{(i)}\right. \\
& \left.+p_{y} v^{(i)}\right) d s \\
& N_{y}{ }^{(k)}(\varphi)=-\int_{0}^{h}\left(\frac{1}{R_{i k}} N_{\varphi y}{ }^{\prime} \gamma^{(k)}-N_{y} \dot{v}^{(k)}\right. \\
& \left.+p_{y} v^{(k)}\right) d s \\
& Q_{y}^{(i)}(\varphi)=-\int_{0}^{h}\left(\frac{1}{R_{i k}{ }^{2}} M_{\varphi}{ }^{\prime \prime} u^{(i)}-\frac{2}{R_{i k}} M_{\varphi y^{\prime}} \dot{u}^{(i)}\right. \\
& \left.+M_{y} \ddot{u}^{(i)}-\frac{N_{\varphi}}{R_{i k}} u^{(i)}+p_{r} u^{(i)}\right) d s \\
& Q_{y}{ }^{(k)}(\varphi)=-\int_{0}^{h}\left(\frac{1}{R_{i k}{ }^{2}} M_{\varphi}{ }^{\prime \prime} u^{(k)}-\frac{2}{R_{i k}} M_{\varphi y^{\prime}} \dot{u}^{(k)}\right. \\
& \left.+M_{y} \ddot{u}^{(k)}-\frac{N_{\varphi}}{R_{i k}} u^{(k)}+p_{r} u^{(k)}\right) d s
\end{aligned}
$$

$$
\begin{aligned}
M_{y}{ }^{(i)}(\varphi)= & -\int_{0}^{h}\left(\frac{1}{R_{i k}{ }^{2}} M_{\varphi}^{\prime \prime} \theta^{(i)}-\frac{2}{R_{i k}} M_{\varphi y^{\prime}} \dot{\theta}^{(i)}\right. \\
& \left.+M_{y} \ddot{\theta}^{(i)}-\frac{N_{\varphi}}{R_{i k}} \theta^{(i)}+p_{r} \theta^{(i)}\right) d s
\end{aligned}
$$

$$
\begin{aligned}
M_{y}^{(k)}(\varphi)= & -\int_{0}^{h}\left(\frac{1}{R_{i k}{ }^{2}} M_{\varphi}^{\prime \prime} \theta^{(k)}-\frac{2}{R_{i k}} M_{\varphi y^{\prime}} \dot{\theta}^{(k)}\right. \\
& \left.+M_{y} \ddot{\theta}^{(k)}-\frac{N_{\varphi}}{R_{i k}} \theta^{(k)}+p_{r} \theta^{(k)}\right) d s
\end{aligned}
$$

ここで, $N_{\varphi y^{(i)}}, N_{\varphi y^{(k)}}, N_{y}^{(i)}, N_{y}^{(k)}, Q_{y}^{(i)}, Q_{y}{ }^{(k)}$, $M_{y}{ }^{(i)}, M_{y}{ }^{(k)}$ はそれぞれ, 節線 $i i^{\prime}, k k^{\prime}$ に作用する $\varphi$, $y, r$ 軸方向外力荷重および $\varphi$ 軸まわり外力モーメント である。ただし， $Q_{y}{ }^{(i)}, Q_{y}{ }^{(k)}$ は次式で表わされる等価 せん断力を考えている。

$$
Q_{y}{ }^{(i)}=-\left[M_{y} \cdot+\frac{2}{R_{i k}} M_{\varphi y^{\prime}}\right]_{s=0}
$$




$$
Q_{y}{ }^{(k)}=\left[M_{y} \cdot+\frac{2}{R_{i k}} M_{\varphi y^{\prime}}^{\prime}\right]_{s=h}
$$

式 (17)より式 (12)，(13)，(14)，(15）を利用して変 形すれば, 次のマトリクス表示式が導かれる。

$$
\begin{aligned}
\{\boldsymbol{P}\} & =\left[\left[\boldsymbol{K}_{1}{ }^{s h}\right]\left(\frac{d}{d \varphi}\right)^{4}+\left[\boldsymbol{K}_{2}{ }^{s h}\right]\left(\frac{d}{d \varphi}\right)^{2}\right. \\
& \left.+\left[\boldsymbol{K}_{3}{ }^{s h}\right]\left(\frac{d}{d \varphi}\right)+\left[\boldsymbol{K}_{4}{ }^{s h}\right]\right]\{\boldsymbol{\delta}\} \quad \cdots \cdots . . .
\end{aligned}
$$

ここで, $\{\boldsymbol{P}\}$ および $\{\boldsymbol{\delta}\}$ は節線外力および節線変位 のベクトルであり, 次に示すものである。

$$
\{\boldsymbol{P}\}=\left\{\begin{array}{ll}
N_{\varphi y^{(i)}}(\varphi) \\
Q_{y}{ }^{(i)} & (\varphi) \\
N_{y}{ }^{(i)} & (\varphi) \\
M_{y}{ }^{(i)} & (\varphi) \\
N_{\varphi y}{ }^{(k)} & (\varphi) \\
Q_{y}{ }^{(k)} & (\varphi) \\
N_{y}{ }^{(k)} & (\varphi) \\
M_{y}{ }^{(k)} & (\varphi)
\end{array}\right\},\{\boldsymbol{\delta}\}=\left\{\begin{array}{c}
w_{i}(\varphi) \\
u_{i}(\varphi) \\
v_{i}(\varphi) \\
\theta_{i}(\varphi) \\
w_{k}(\varphi) \\
u_{k}(\varphi) \\
v_{k}(\varphi) \\
\theta_{k}(\varphi)
\end{array}\right\} \cdots
$$

$\left[\boldsymbol{K}_{1}^{s h}\right],\left[\boldsymbol{K}_{2}^{s h}\right],\left[\boldsymbol{K}_{3}^{s h}\right]$ および $\left[\boldsymbol{K}_{4}^{s h}\right]$ は用性マト リクスで, 表一1，2，3，4 に示すとおりである。

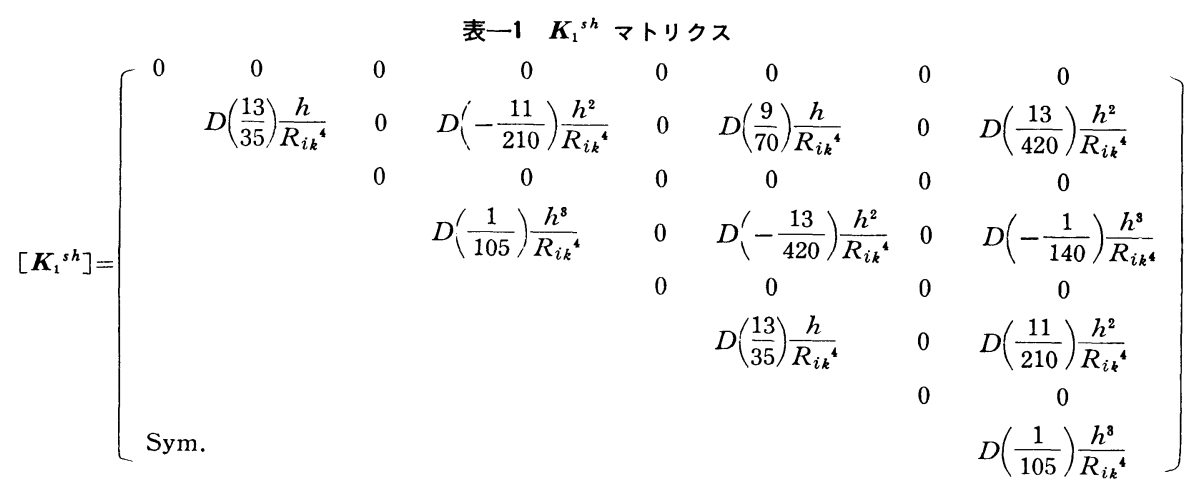

$$
\begin{aligned}
& \text { 表一2 } \boldsymbol{K}_{2}{ }^{\text {sh }} \text { マトリクス } \\
& {\left[{K_{2}}^{s h}\right]=\left\{\begin{array}{l}
F\left(-\frac{1}{3}\right) \\
\text { Sym. }
\end{array}\right.} \\
& 0 \quad F\left(-\frac{1}{6}\right) \frac{h}{R_{i k}^{2}} \quad 0 \quad 00 \\
& D\left(-\frac{12}{5}\right) \frac{1}{h R^{2}{ }_{i k}} \quad 0 \quad D\left(\nu+\frac{1}{5}\right) \frac{1}{R_{i k}{ }^{2}} \quad 0 \quad 0 \quad D\left(\frac{12}{5}\right) \frac{1}{h R_{i k}{ }^{2}} \quad 0 \quad D\left(\frac{1}{5}\right) \frac{1}{R_{i k}{ }^{2}} \\
& F\left(-\frac{1-\nu}{6}\right) \frac{h}{R_{i k}{ }^{2}} \quad 0 \quad 0 \quad 0 \quad 0 \quad F\left(-\frac{1-\nu}{12}\right) \frac{h}{R_{i k}{ }^{2}} \quad 0 \\
& D\left(-\frac{4}{15}\right) \frac{h}{R_{i k}{ }^{2}} \quad 0 \quad D\left(-\frac{1}{5}\right) \frac{1}{R_{i k}{ }^{2}} \quad 0 \quad D\left(\frac{1}{15}\right) \frac{h}{R_{i k}{ }^{2}} \\
& F\left(-\frac{1}{3}\right) \frac{h}{R_{i k}{ }^{2}} \quad 0 \quad 00 \\
& D\left(-\frac{12}{5}\right) \frac{1}{h R_{i k}^{2}} \quad 0 \quad D\left(-\nu-\frac{1}{5}\right) \frac{1}{R_{i k}^{2}} \\
& F\left(-\frac{1-\nu}{6}\right) \frac{h}{R_{i k}^{2}} \quad 0 \\
& \left.D\left(-\frac{4}{15}\right) \frac{h}{R_{i k}^{2}}\right]
\end{aligned}
$$

表一3 $K_{3}{ }^{\text {sh }}$ マトリクス

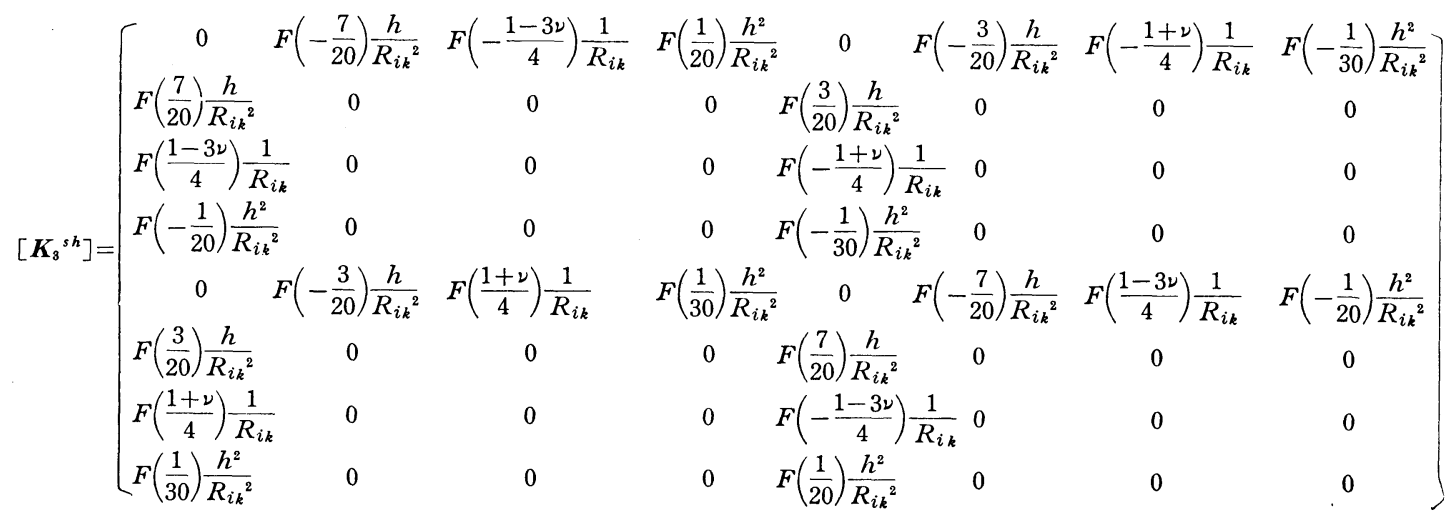




$$
\begin{aligned}
& \text { 表一4 } K_{4}^{s h} \text { マトリクス }
\end{aligned}
$$

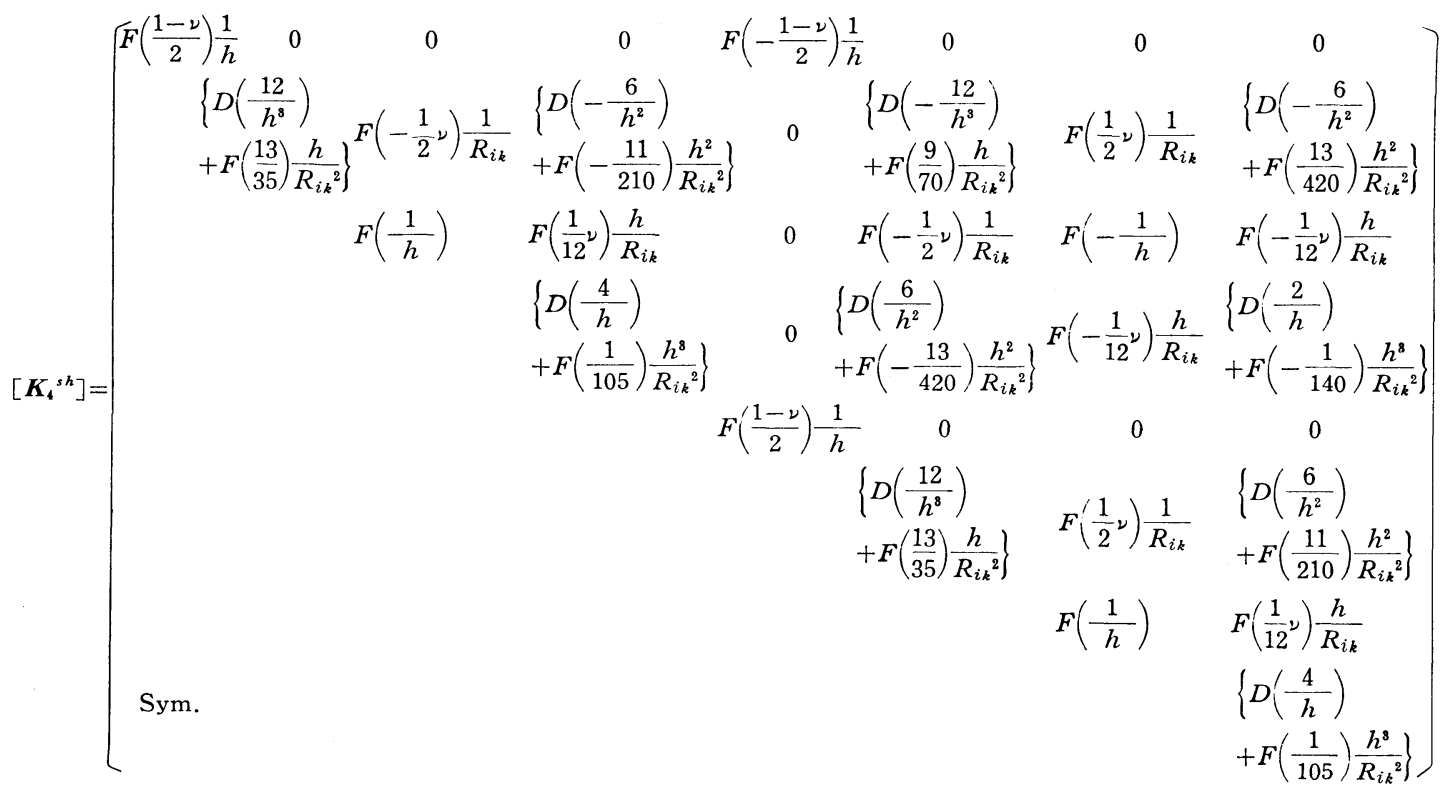

\section{3. 数值解析例}

\section{（1）両端単純支持された異方性扇形平板の曲げ問題}

図-4 に示寸両端単純支持の扇形平板を解析寸る。こ の問題は文献 38)に扔いて, 解析および実験が行われ ている。実験モデルは扇形平板と 6 本の補強 T型ばりと から成る。本解析ではこれを異方性板とみなし，その剛 性は文献 28）によって与えられた值を使用した。この平 板を等間隔に 5 要素に分割し，図一4のよ5に節線 $11^{\prime}, 22^{\prime}, \cdots \cdots, 66^{\prime}$ を定めた。また，軸方向の位置を示す 便宜上，等間隔に $R_{1}, R_{2}, \cdots \cdots, R_{6}, L_{1}, L_{2}, \cdots \cdots, L_{6}$ の線を採っている。

扇形平板の寸法および曲げ剛性は次のとおりである。

断面の幅

$38.1 \mathrm{~cm}$ (15 in.)

中心角

$102^{\circ}$

$D_{r}$

$0.5496 \times 10^{3} \mathrm{~kg}-\mathrm{cm}$

$\left(0.4770 \times 10^{3}\right.$ lb.-in.)

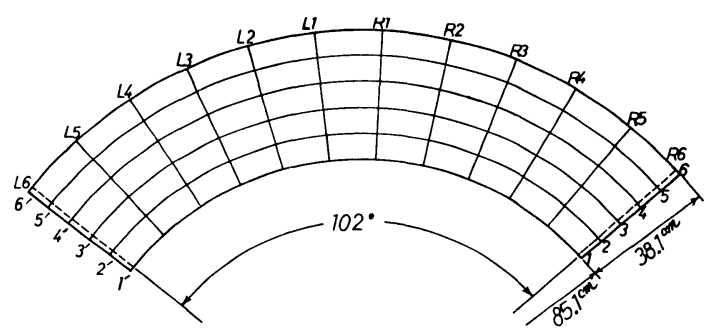

図一4儌形平板の計算モテル
$D_{\varphi} \quad 3031 \times 10^{3} \mathrm{~kg}-\mathrm{cm}\left(2631 \times 10^{3}\right.$ lb.-in. $)$

$D_{k} \quad 15.90 \times 10^{3} \mathrm{~kg}-\mathrm{cm}\left(13.80 \times 10^{3}\right.$ lb.-in. $)$ ポアソン比 $\left(\nu_{r}, \nu_{\varphi}\right) \quad 0$

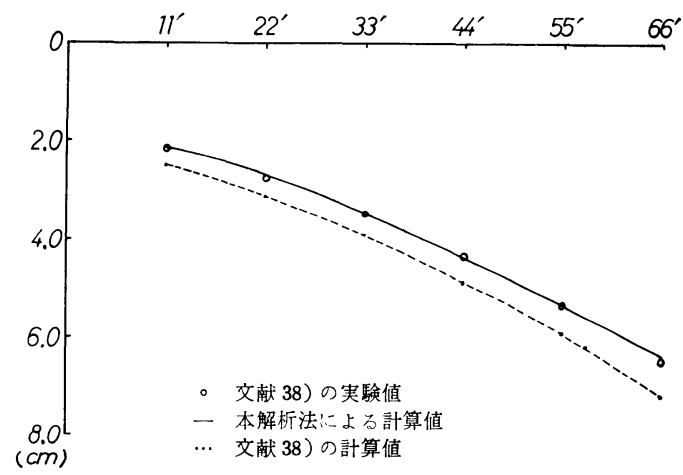

図一5(a) L1 上のたわみ分布

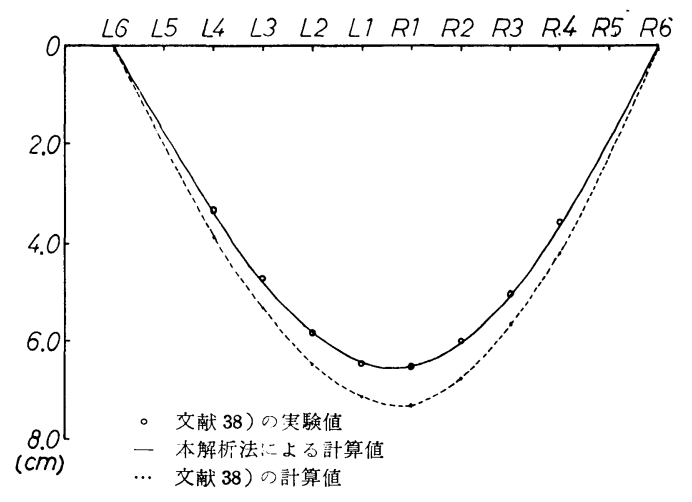

図一5(b) 節線 66' 上のたわみ分布 
荷重としては，R3 と節線 $11^{\prime}, 22^{\prime}, \cdots \cdots, 66^{\prime}$ の交差 する点に, 面外方向にそれぞれ $22.68 \mathrm{~kg}(50 \mathrm{lb}$.) が載荷 されている。

図一5 は本解析法による計算結果と, 文献 38) に示さ れた Heins らの実験結果ならびに彼らの計算結果を図示 したものである。図一5(a) は L 1 上のたわみ分布, 図 -5(b) は節線 $66^{\prime}$ 上のたわみ分布を示している。本解 析法による值は, Fourier 級数の 5 項までの結果である が, Heins らの計算值と比較しても実験值と良く一致し ていることがわかる。

\section{（2）薄肉箱型はりのずり問題}

図一6に示す両端単純支持の薄肉箱型はりを解析す る。要素分割は扇形板要素 2 枚, 曲板要素 2 枚, 合計 4 要素である。両端には面内剛性無限大のダイヤフラムが 入っているものとする。中間ダイヤフラムは, 全くない 場合，スパン中央に 1 枚入っている場合，およびスパン 中央と $1 / 4,3 / 4$ 点に合計 3 枚入っている場合の 3 ケース について考えられている。中間ダイヤフラムの取扱いに

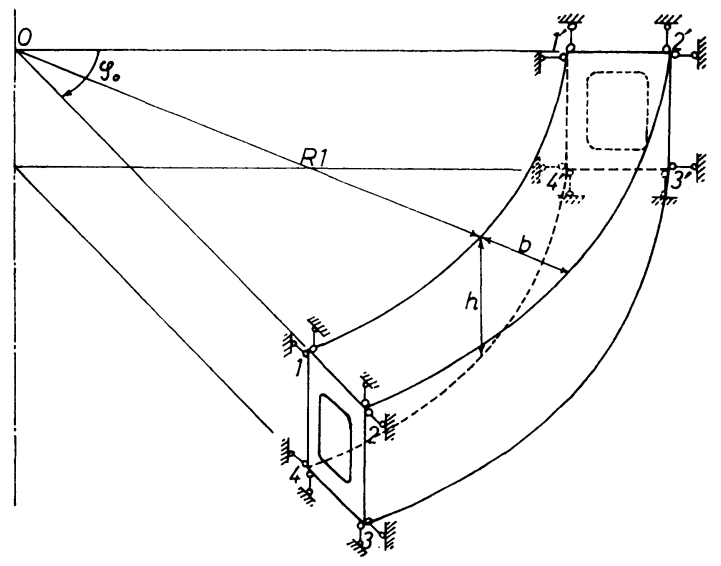

図一6薄肉箱型はりの計算モデル

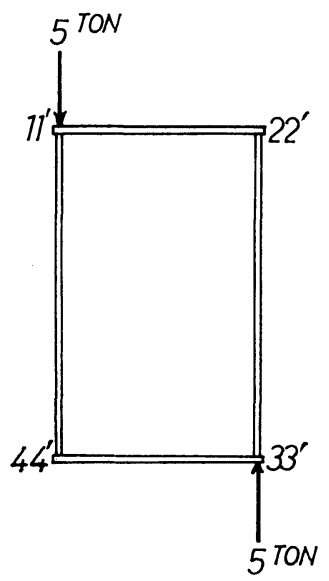

図一7 スパン中央のずり荷重
ついては, ダイヤフラムを二次元平板として求めた有限 要素剛性マトリクスを薄肉はりの剛性マトリクスに組み 入れることにより考慮することができる。

計算に用いたモデルの寸法および材料定数は次のとお りである。

$\begin{array}{ll}\text { 断面の高さ } & h=50 \mathrm{~cm} \\ \text { 断面の幅 } & b=30 \mathrm{~cm} \\ \text { 断面の図心までの曲率半径 } & R_{1}+b / 2=5 \mathrm{~m} \\ \text { 中心角 } & \varphi_{0}=1 \mathrm{radian} \\ \text { 上下フランジ板厚 } & t_{f}=0.6 \mathrm{~cm} \\ \text { ウェブ板厚 } & t_{w}=0.6 \mathrm{~cm} \\ \text { 中間ダイヤフラム板厚 } & t_{D}=2.0 \mathrm{~cm} \\ \text { ヤング率 } & 2.1 \times 10^{6} \mathrm{~kg} / \mathrm{cm}^{2} \\ \text { ポアソン比 } & 0.3\end{array}$

荷重はスパン中央に図一7に示すように, 内外のウェ ブ位置にそれぞれ 5 ton のずり荷重を載荷した。

図一8 は節線 $33^{\prime}, 44^{\prime}$ の上下方向変位（下向きが正） について, 本解析法 (級数項数 5 ) による計算值と, 別

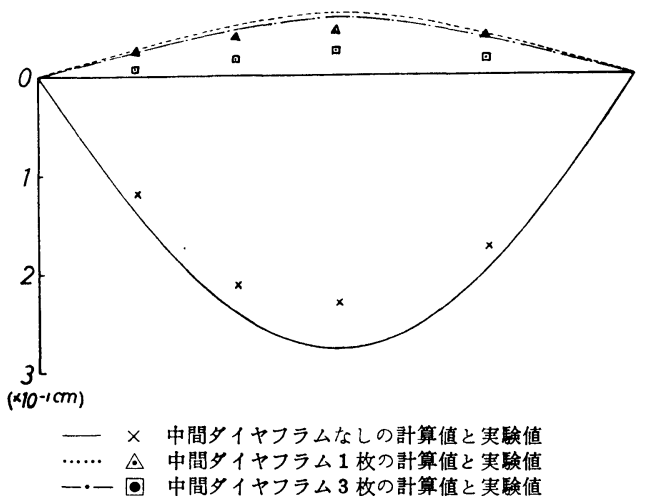

図一8(a) 節線 $33^{\prime}$ の上下方向変位

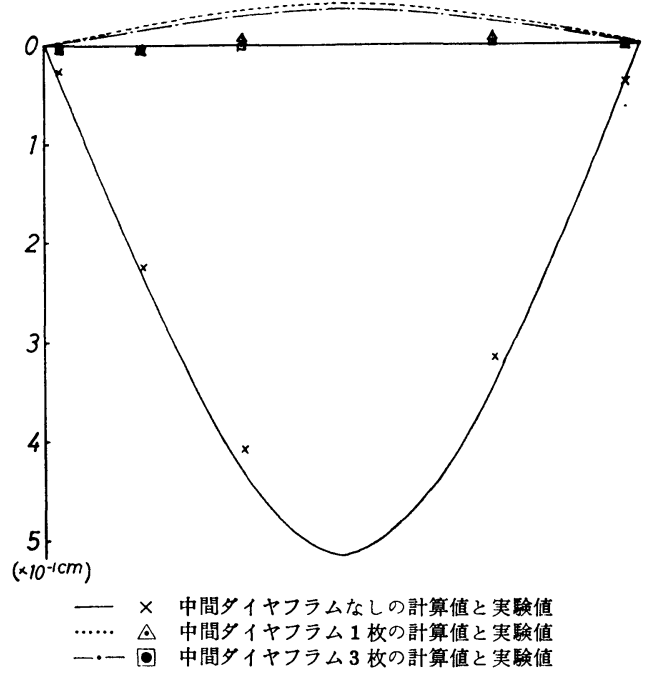

図一8（b）節線 44' の上下方向变位 
途23) 行われた模型実験による值を図示したものであ る。計算值が実験值より若干大き目の值を与え, また中 間ダイヤフラムが入る場合については，両者の間にかな りの相違も見られるが, 結果はまず良いものと思われ る。相違の原因としては, 実験における端部支持条件充 足の難かしさと中間ダイヤフラムの入る場合, 変位絶対 量の小さいことなどが考えられよう。

図一9 はスパンの $1 / 3$ 断面の変位形状を模式的に図示 したものである。中間ダイヤフラムの入らない場合と入 る場合とで断面形状の変化における相違が明確に認めら れる。特に中間ダイヤフラムの入らない場合の変形に特 徵が見られる。

図一10 は中間ダイヤフラムをスパン中央に 1 枚入れ た場合について, ダイヤフラム板厚のみを $2 \mathrm{~cm}$ から順 次減少させて計算した時の結果である。ダイヤフラム板 厚が $0.4 \mathrm{~cm}$ 以下になるにしたがい, 急速にダイヤフラ ムの効果が失われていく様子が認められる。このような 計算はダイヤフラムの設計資料を与える意味から今後有 用となろう。

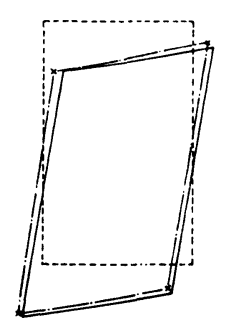

(a)

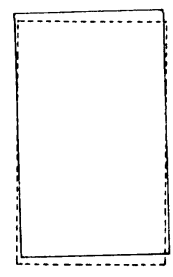

(b)

\section{計算値}

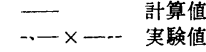

a) 中間ダイヤフラムなし b）中間ダイヤフラム 1 枚 c）中間ダイヤフラム 3 枚

\section{図一9 断面の変形状態}

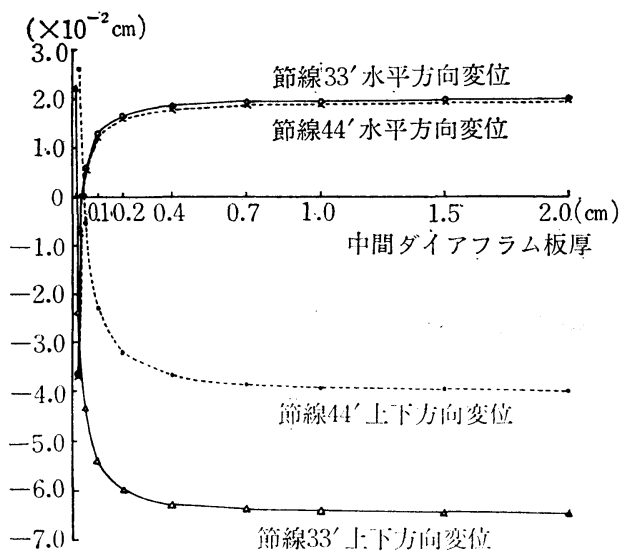

図一10 中間ダイヤフラム（スパン中央）板厚と变位の関係

\section{4. むすび}

以上から，本論文を要約すると以下のようになる。

（1）重みつき残差法としての Galerkin 法の適用に よって, Cheung などの有限帯板法とほとんど同一の剛 性マトリックス式を得た。しかしながら，その場合重み 関数の選び方によっては相反作用則を充足しないことが あるので注意を要する。

（2）異方性扇形板の曲げ解析の結果は, 既往研究の 結果と良く一致した。

（3）曲線箱ばりの模型実験の結果と, 本解析法の結 果との対比によれば, ダイヤフラムの影響を含めて両者 はほぼ良く一致した。若干の相違は実験誤差（特に支承 条件）に起因すると思われる。

本論文は筆者らが東京大学大学院在学中に行った研究 に基づく所が多い。ご指導と有益なご助言を載いた工学 部土木工学科 奥村敏恵教授ならびに同綜合試験所 西 野文雄助教授に厚く感謝の意を表します。

\section{参 考 文 献}

1) Gottfeld, H.: Die Berechnung raumlich gekrummter Stahlbrucken. Baurechnik 1932, s. 715

2) Umanskij, A.A.: Raumliche Tragwerke, Moskau 1948 (Russisch)

3) Wansleben, F.: Die Berechnung drehfester gekrummter Stahlbrucken. Stahlbau 1952, s. 53

4) Vlasov, V.Z.: Thin-walled Elastic Beams. Publ. for the National Science Foundation, 1961

5) Dabrowski, R.: Gekrummte dunnwandige Trager. Springer-Verlag, 1968

6) 平井 敦・倉西 茂: 曲線橋の理論について, 土木技術, 昭和33年 7 月

7）小西一郎・小松定夫: 薄肉曲線析の基礎理論, 土木学会論 文集, 第 87 号, 昭和 37 年 11 月

8）小西一郎- 小松定夫：単純支持曲線析橋の立体的解析, 土 木学会論文集, 第 90 号, 昭和 38 年 2 月

9）小西一郎・小松定夫: 薄肉連続曲線析橋の立体的解析, 土 木学会論文集, 第 91 号, 昭和 38 年 3 月

10）小松定夫：曲線並列析橋の実用計算式, 土木学会論文集, 第 93 号, 昭和 38 年 5 月

11）合西 茂: 一般薄肉断面の曲りばりの解析, 土木学会論文 集, 第 108 号, 昭和 39 年 8 月

12）島田静雄・倉西 茂: 曲りばりの計算式, 技報堂, 昭和41年

13）深沢泰晴: 薄肉曲線材の静力学的解析関する基礎的理 論, 土木学会論文集, 第 110 号, 昭和 39 年 10 月

14）深沢泰晴：せえ断中心軸の不連続性を考虑した変断面薄肉 曲線桁の解析法, 第 14 回橋梁構造工学研究発表会論文集, 1967

15）芳村 仁：曲線直交異方性変厚扇形平板の曲げについて, 土木学会論文集, 第 86 号, 昭和 37 年 10 月

16）遠藤篤康：多角形曲線橋理論，士木技術，昭和 35 年 10 月

17) Becker, G.: Ein Beitrag zur statischen Berechnung beliebig gelagerter gekrummter ebener Stabe mit einfach-symmetrischen dunnwandigen offenen Profilen von in Stabachse veranderlichem Querschnitt 
unter Berucksichtigung der Wolbkrafttorsion. Stahlbau 1965, s. 334

18）㝓西 茂: 曲線格子桁の解法, 土木学会論文集, 第 76 号, 昭和 36 年 9 月

19）西野文雄・Lee, Seng-Lip：薄肉断面曲線はりの基礎方程 式, 第 28 回土木学会年次学術講演概要集, 昭和 48 年

20) McManus, P.F., Nasir, G.A. and Culver, C.G.: Horizontally Curved Girders-State of the Art, Proc. ASCE, Vol. 95, No. ST 5, May, 1969

21）落合重俊：多室断面げたの力学的性状について, 東京大学 大学院博士論文, 昭和 41 年

22）能町純雄・吉田紘一：断面変形を考慮した曲線箱䘕の応力 解析, 土木学会論文報告集, 第 187 号, 昭和 46 年 3 月

23）坂井藤一: 平板ないし曲面板より成る薄肉立体構造物の力 学的性状について, 東京大学大学院工学系研究科博士論 文, 昭和 45 年

24）坂井藤一：曲線箱げたの断面変形とダイアフラムの影響, 関西支部年次学術講演概要集, 昭和 46 年

25）青野捷人：断面変形を考虑した曲線箱げた解析, 東京大学 大学院工学系研究科修士論文, 昭和 46 年

26) Chu, K.H. and Pinjarkar, S.G.: Analysis of Horizontally Curved Box Girder Bridges, Proc. ASCE, Vol. 97, No. St 10, Oct., 1971

27) Meyer, C. and Scordelis, A. C.: Analysis of Curved Folded Plate Structures, Proc. ASCE, Vol. 97, No. St 10, Oct., 1971

28) Buragohain, D.N. and Agrawal, B.L.: Analysis of Curved Box Girder Bridges, Proc. ASCE, Vol. 99, No. St 5, May, 1973

29）小松定夫-中井 博- 北田俊行：曲線桁橋の Shear lag と有効幅に関する研究, 土木学会論文報告集, 第 191 号, 昭和 46 年 7 月

30）薄木征三・菅原 登：曲線箱桁のフランジ有効幅について 第 23 回土木学会年次学術講演概要集, 昭和 43 年

31）芳村 仁・菲沢憲吉：折板理論解析による曲線桁橋の床版 応力と有効幅について，土木学会論文報告集，第 233 号， pp. $45 \sim 54,1974$ 年 12 月

32) Culver, C.G. and Frampton, R.E.: Local Instability of Horizontally Curved Members, Proc. ASCE, Vol. 96, No. ST 2, Feb., 1970

33) Culver, C.G., Dym, C.L. and Brogan, D.K.: Ben- ding Behavior of Cylindrical Panels, Proc. ASCE, Vol. 98, No. ST 10, Oct., 1972

34) Mariani, N., Mozer, J.D., Dym, C.L. and Culver, C.G. : Transverse Stiffener Requirements for Curved Webs, Proc. ASCE, Vol. 99, No. ST 4, April, 1973

35) Abdel-Sayed, G.: Curved Webs under Combined Shear and Normal Stresses, Proc. ASCE, Vol. 99, No. ST 3, March, 1973

36） 米沢 博 -三上市蔵他：扇形板の曲げ座屈(近似解), 第 24 回土木学会年次学術講演概要集, 昭和 44 年

37) Coull, A. and Das, P.C.: Analysis of Curved Bridge Decks, Proc. ICE, Vol. 37, May, 1967

38) Heins, C.P.Jr. and Hails, R.L.: Behavior of Stiffened Curved Plate Model, Proc. ASCE, Vol. 95, No. ST 11, Nov., 1969

39) Buragohain, D.N.: Discrete Analysis of Cylindrical Orthotropic Curved Bridge Decks, Publ. IABSE, Vol. 32, 1972

40) Cheung, Y.K.: The Analysis of Cylindrical Orthotropic Curved Bridge Decks, Publ. IABSE, Vol. 29,1969

41）大宮司尚・Vallabhan, C.V.G.: 有限帯板法による曲鋼 床版の解析, マトリックス構造解析 シンポジウム, JSSC, 1973

42) Yonezawa, H.: Moments and Free Vibrations in Curved Girder Bridges, Proc. ASCE, Vol. 88, No. EM 1, Feb., 1962

43) Cheung, Y.K.: Free Vibration of Curved and Straight Beam-Slab of Box-Girder Bridges, Publ. IABSE, Vol. 32, 1972

44）奥村敏恵・坂井藤一: 薄肉平板より成る立体的構造物の静 力学的解析に関する一方法とその応用, 土木学会論文報告 集, 第 176 号, 昭和 45 年 4 月

45) Cheung, Y.K.: The Finite Strip Method in the Analysis of Elastic Plates with Two opposite Simply Supported Ends, Proc. ICE, May, 1968

46) Powell, G.H. and Ogden, D.W.: Analysis of Orthotropic Plate Bridge Decks, Proc. ASCE, Vol. 95, No. ST 5, May, 1969

47）軽構造の理論とその応用，林毅編，日科技連，昭和 41 年 (1974. 9. 18. 受付) 